\title{
Observación participante y distancia antropológica
}

M.' ISABEL JOCILES RUBIO Universidad Complutense

A Juan Jociles Bejarano, in memoriam

\section{INTRODUCCIÓN}

En este estudio presento una reflexión sobre qué es la observación participante, así como sobre el papel que 'la distancia' desempeña —en mi opinión- dentro de las investigaciones antropológicas; una reflexión que toma como eje argumental (quizá también como excusa) el comentario de un texto de Juan Manuel Delgado y Juan Gutiérrez, precisamente porque es fruto de la lectura crítica de uno de los capítulos, de los dos debidos a su pluma, que publican en una obra colectiva coordinada también por ellos: Métodos y técnicas cualitativas de investigación en ciencias sociales. Se trata del titulado "La teoría de la observación" ${ }^{1}$ y, más en concreto, de la parte que dedican a caracterizar (y, a menudo, a caricaturizar) la observación participante, puesto que la otra —que dejaré más de lado- se centra en lo que denominan autoobservación. Es un capítulo que, para responder de modo más apropiado a la naturaleza de su contenido, habría tenido que llamarse algo así como 'De cómo vincular la observación participante a la antropología social para descartar a ambas como aptas para el estudio de las sociedades complejas'. Abro así estas páginas con el fin de anunciar, ya desde la primera de ellas, de qué voy a hablar, con qué tono y desde qué planteamientos, si se tiene en cuenta - por otro lado- que estoy convencida de que la observación participante, insertada en proyectos que la combinan con otras técnicas cualitativas y/o cuantitativas —que es lo que ocurre, en realidad, en todas $o$

1 Delgado, J. M. y Gutiérrez, J., "La teoría de la observación", en Delgado, J. M. Y GuTIÉRREZ, J. (coords.), Métodos y técnicas cualitativas de investigación en ciencias sociales (Madrid: Síntesis, 1994), pp. 141-154. En adelante, las referencias a esta obra se harán señalando únicamente el número de los páginas correspondientes. 
casi todas las investigaciones etnográficas ${ }^{2}$-, es tanto o más válida que otras para acercarse al conocimiento de las sociedades complejas, y que voy a defender esta idea en un diálogo abierto con el texto mencionado hace un momento.

\section{LA OBSERVACIÓN PARTICIPANTE}

Entrando ya en materia, es preciso empezar por la tipología que Delgado y Gutiérrez establecen de las diferentes modalidades de observación, según la cual - y a partir del primer criterio que manejan (la distinción entre exógeno y endógeno) - la observación participante constituiría "el modo de observación más representativo de la observación exógena", mientras que la autoobservación lo sería de la "observación endógena", por cuanto:

Basta advertir que observador y actor son posiciones y no personas o especialistas inamovibles en el curso de una interacción. Por ejemplo, será una posición derivada aquella en que el observador-actor actúa sobre otro, sin que éste tenga conciencia de la existencia de un observador, aunque sí del actor (forma derivada de la situación pura actuar-sobre-otro). También es una forma derivada de la situación pura de actuar-sobre-otro aquella en que el observador-actor está orientado hacia el otro, percibiéndolo éste en su doble dimensión de observador y actor. A su vez, un ejemplo de forma derivada de la relación -nosotros en orientación-otro viene dado por aquella situación en que el actor (posteriormente observador) está simplemente orientado hacia el otro y en actitud natural (Schutz, 1972)/ Las dos primeras derivaciones se corresponden con la observación participante (para abreviar OP), mientras que la última mencionada se refiere a la autoobservación [en adelante $\mathrm{AO}]^{3}$.

La clasificación de la observación participante entre las atecnologías exógenas" resulta fácil de ver, al menos si se aceptan distinciones como la precedente, aunque no sean las que, por lo general, establecen los antropólogos. Y digo esto por una razón principal: Delgado y Gutiérrez identifican la autoobservación no sólo por el hecho de que el observador pertenezca al grupo que investiga, sino por tratarse de una aautoobservación

2 Ver, por ejemplo, SANMARTín, R., "La observación participante", en García FERRANDO, M. Y OTROS, El análisis de la realidad social (Madrid: Alianza, 1989), p. 132. Subrayo lo de casi todas en la anterior frase, sobre todo, para evitar la tentación del "bongo-bongoísmo": no sea que se haya realizado alguna etnografía, por muy desconocida que sea, que no haya recurrido a otra técnica salvo a la observación participante.

3 P. 142. 
diferida por parte de los propios actores ${ }^{4}$, es decir, porque alguien se convierte en observador retrospectivo de una situación en que participó sólo como actor y a la que se enfrentó con "una actitud natural". Así - cabe deducir que- los registros de información de los que el autoobservador se vale son, principalmente, su propia memoria y/o los documentos (notas, diarios, informes..) que produjo en su condición de actor. Sin embargo, también advierten que la autoobservación es únicamente "uno de los modos de observación posible dentro de las tecnologías de la observación endógena" ${ }^{5}$, sin señalar —empero- cuáles son esos otros modos ni si su identificación como tales está en función de que se estudie el propio grupo o de que exista un lapso temporal entre la condición de actor y observador. Es justamente la primera posibilidad la que da pie para pensar que la tipología puede que no sea muy adecuada, sobre todo porque estudiar el propio grupo no entraña necesariamente el renunciar a la observación participante o el tener que acercarse a él con uactitud natural" (que esto último sea así, o no, dependerá, entre otras cosas, del grado de vigilancia epistemológica que el investigador ejerza sobre su trabajo). De hecho, Spradley ${ }^{6}$, v.g., considera la observación del propio grupo como una más de las modalidades de uso de la observación participante en antropología social. Ahora bien, él está pensando en un observador que está interactuando y observando al grupo del que es también actor, es decir, que registra mientras es observador, lo que no quita para que en la práctica también utilice registros procedentes de una posición anterior de sólo actor.

Con todo - como se ha comentado- si se admite el esquema propuesto por Delgado y Gutiérrez, la pertenencia de la observación participante a las tecnologías exógenas resulta, al menos, clara; lo cual no puede decirse de su inclusión dentro de otros tipos, como los procedentes de diferenciar entre observación cualitativa externa y observación cualitativa interna, y ello a pesar de afirmaciones como ésta:

Vamos a entender por observación participante, a secas, una observación interna o participante activa, en permanente 'proceso lanzadera', que funciona como observación sistematizada natural de grupos reales o comunidades en su vida cotidiana, y que fundamentalmente emplea la estrategia empírica y las técnicas de registro cualitativas (Anguera, 1989: 128-143) ${ }^{\text {? }}$.

4 P. 142

5 P. 142

6 Spradley, J. P., Participant Observation (New York: Holt. Rinehart \& Winston, 1980), pp. 61 y ss.

7 P. 144. 
¿De dónde puede provenir, entonces, esa falta de claridad? Pues, de cómo se fija - por ejemplo- su antónimo, la observación cualitativa externa, dado que en algunas ocasiones es definida a partir de elementos metodológicos (no pertenecer ni participar en el grupo investigado), mientras que en otras lo que se hace entrar en la definición son elementos teórico-epistemológicos (contemplar la realidad como una relación entre estímulos y respuestas), tal como cabe apreciar a través de la siguiente cita:

(D)iremos que la observación cualitativa externa, es decir, aquella en que el observador, empleando técnicas de registro cualitativas (registro de acontecimientos, conducta no verbal ${ }^{8}$, categorización de comportamientos, etc.) no pertenece ni participa en el grupo objeto de estudio, bien se trate de observación directa (en contacto, sobre el terreno) o indirecta (fuentes documentales) posee unas implicaciones teóricas, unos presupuestos epistemológicos y unos condicionamientos metodológicos que la aproximan a las investigaciones realizadas mediante observaciones con registros cuantitativos en el ámbito de la psicología, la sociología, la historia, etc. El sujeto aparece tratado como una función que relaciona con regularidad unas entradas o estímulos con unas salidas o respuestas. Los procesos cognitivos de la mente humana quedan fuera de las respuestas conductuales registrables cuantitativamente ${ }^{9}$. La historia del pensamiento occidental nos indica que esa anulación de la complejidad del sujeto, su capacidad selectiva y productora de sentido, y su potencialidad transformadora conduce a una visión mecánica y reproductora de las sociedades y los sistemas ${ }^{10}$.

Esta mezcolanza (que no integración teórica) de aspectos técnicos, metodológicos, epistemológicos y ontológicos a la hora de delinear una técnica de investigación (o una metodología) no deja de ocasionar perplejidades a quien se haya molestado en conocer, aunque sea superficialmente, la historia de su uso en investigaciones concretas o las potencialidades que entraña; unas perplejidades que son provocadas al lector desde el principio y que, como intentaré poner de manifiesto más tarde, se originan - entre otras cosas- en una concepción de las metodologías de investigación como paradigmas, ya suficientemente criticada —entre otrospor Cook y Reichardt ${ }^{11}$ o Hammersley ${ }^{12}$. En cualquier caso, lo que sí se

8 ¿Por qué no igualmente la conducta verbal?, ¿no es también registrable cualitativamente cuando el observador "no pertenece ni participa en el grupo objeto de estudio"?

9 ¿Acaso "los procesos cognitivos de la mente humana" quedan dentro de las respuestas conductuales registrables cualititativamente o de cualquier otro modo?

10 Pp. 142-143.

11 COOK, T. D. y REICHARDR, C. S., "Hacia una superación del enfrentamiento entre los métodos cualitativos y cuantitativos", en COOK, T. D. y REICHARDR, C. S. (eds.), Métodos cualitativos y cuantitativos en investigación evaluativa (Madrid: Morata, 1986 -1982-).

12 Hammersley, M., The politics of social research (London: Sage, 1995). 
puede colegir de los párrafos precedentes es que si la OP no es observación externa, sería de esperar que tuviera en cuenta "la complejidad de los sujetos" así como "los procesos simbólicos y cognitivos de la mente humana", esto es, que no los obviara y/o no los enfocara como una "función que relaciona con regularidad unas entradas o estímulos con unas salidas o respuestas", que son las dos "implicaciones teóricas, presupuestos epistemológicos y condicionamientos metodológicos" que Delgado y Gutiérrez evocan (al menos a estas alturas del texto) con respecto de la "observación con registros cuantitativos" y, en este caso también (por la proximidad que perciben entre ambas), de la "observación cualitativa externa". Pero la capacidad deductiva del lector (azuzada, además, por ciertas palabras del comienzo ${ }^{13}$ ) se verá constantemente frustrada o contradicha por una suerte de juego de sorpresas que se le irá deparando conforme avance la narración:

\begin{abstract}
...Si bien es cierto que la observación participante posee una alternativa de mayor implicación comprensiva respecto a una sociología objetivista, todavía puede decirse que la observación participante funciona como una sociología positiva, pues genera un producto (culturas, identidades) para el que reclama estatuto ontológico y una gran capacidad para orientar la acción social. Muy lejos de un subjetivismo, por el contrario, pretendiendo controlar/producir una forma de subjetividad racional de la colectividad..., la observación participante pierde la referencia de la categoría de sujeto..., no alcanza una teoría compleja y unitaria de la mente humana, y practica una ocultación activa de la preocupación constante que el analista-participante despliega sobre el sí mismo ${ }^{14}$.
\end{abstract}

Pero dejemos por ahora esta clase de elucubraciones para volver atrás, a la página 143, en donde nos quedamos antes de presentar estas últimas citas. Allí nos avisan, además, de que no van a abordar cuestiones técnicas de la $\mathrm{OP}$, puesto que los aspectos relacionados con qué tipo de grabadora utilizar y cómo tomar notas de campo y dónde.. "Sólo encuentran sentido en el marco de la discusión de sus presuntas implicaciones

13 "Es en este sentido como afirmamos que las posiciones derivadas expuestas con anterioridad y, en definitiva, la OP y la AO se aproximan y alcanzan, respectivamente, el interior de los sistemas, las mentes y los grupos de estudio y poseen una mayor importancia para la investigación social en tanto que productoras, como tendremos oportunidad de ver, de mayores grados de validez y certezan (p. 143).

14 P. 150. Hay que señalar, incidentalmente, que Delgado y Gutiérrez no toman en consideración las etnografías confesionales que, desde mediados de los 70, han invadido el mercado literario de la antropología desvelando precisamente esa "preocupación constante que el analista-participante despliega sobre el sí mismon; en tal número y tan activamente, además, que han llevado a algunos antropólogos a sostener que la etnografía contemporánea está gravemente aquejada de narcisismo. 
metodológicas y epistemológicas" ${ }^{15}$. Es decir, que una vez que sabemos que la $\mathrm{OP}$ es observación exógena, pero no externa, todo nos mueve a aguardar que vamos a ser embarcados en un análisis de esa suerte de implicaciones. Antes de emprender el viaje, sin embargo, Delgado y Gutiérrez, por un lado, nos comunican que "la observación participante está inevitablemente asociada a la práctica investigadora de los antropólogos sociales y culturales..." ${ }^{16}$, así como que con esto tan sólo advierten de "que esta circunstancia nos aconseja manejar conceptos y ejemplos antropológicos" (ya veremos más adelante cómo manejan los conceptos y de dónde sacan los ejemplos antropológicos); y, por otro lado, enumeran una serie de "condiciones" que - a su parecer- marcan la OP:

1. El antropólogo o investigador en general debe ser un extranjero o extraño a su objeto de estudio.

2. Debe convivir íntegramente en el sistema a estudiar.

3. Ese sistema tiene una definición propia de sus fronteras.

4. La integración del analista será maximizada y funcional, sin dejar de ser por ello un analista externo.

5. El investigador debe escribir una monografía empleando el género del 'realismo etnográfico'.

6. Debe dar por finalizada la circulación del texto y la interpretación con la monografía dirigida a la comunidad académica. El siguiente paso textual, en todo caso, estará constituido por la construcción teórica ${ }^{17}$,

\section{LA DISTANCIA ANTROPOLÓGICA Y LAS SUPUESTAS CONDICIONES DE LA OBSERVACIÓN PARTICIPANTE}

Parémosnos a analizar estas condiciones, dado que buena parte de la argumentación que desarrollan subsiguientemente se basa en la admisión de las mismas como válidas. En primer lugar, hay que decir que apuntan a una representación de la observación participante que parece extraída de la forma en que los postmodernos (y, en especial, Marcus y Cushman ${ }^{18}$ ) la muestran a partir del estudio de las retóricas de la etnografía clásica y

15 Totalmente de acuerdo con esta aseveración. Sin embargo, en el capítulo donde la hacen en ningún momento contextualizan dichas "cuestiones técnicas", al menos no de forma expresa, dentro del marco de las implicaciones metodológicas y epistemológicas que - como dicen- van a constituir el núcleo de su trabajo.

16 P. 143.

17 P. 144.

18 Marcus, G. E. y Cushman, D. E., "Las etnografías como textos", en Geertz, C.; CLIFFORD, J. Y OTROS, El surgimiento de la antropología postmoderna (Barcelona: Gedisa, 1991), pp. 171 y ss. 
que, por tanto, no se corresponde con la visión que de la misma tienen otros posicionamientos antropológicos, ni tampoco con la manera en que desde éstos se ha practicado o se recomienda practicarla. Comencemos por la primera condición mentada. Es cierto, y no pretendo negarlo, que la propia historia de la antropología revela que la mayor parte de los etnógrafos clásicos e, incluso, bastantes de los posteriores han sido extranjeros dentro de las sociedades que investigaban; no en vano, la antropología social es una disciplina occidental (al igual que la mayoría de sus practicantes) que se especializó en el estudio de sociedades no-occidentales ${ }^{19}$. Ahora bien, no se trata tanto de que la práctica de la OP exigiera o exija la extranjeridad geográfica o cultural del investigador (lo digo por esos debes en cursiva), sino de una cuestión que se dio de hecho. Con esto no deseo tampoco recusar la idea de que aun en la actualidad los antropólogos son partidarios - aunque no todos ${ }^{20}$ - del extrañamiento del objeto de estudio, de la mirada distante ${ }^{21} \mathrm{o}$, expresado de otra forma, de convertir en extraño lo que es familiar, de modo que - por ejemploaconsejan a los estudiantes que, en el caso de que deseen estudiar a su propio grupo, antes adquieran una perspectiva transcultural que les permita, entre otras cosas, ser sensibles a la captación de lo obvio, de lo que se da por sabido, de lo que siendo latente no se verbaliza, pero está condicionando las acciones y el discurso de los agentes sociales. Dos estrategias se les suele recomendar para ello: entrenarse antes en el estudio de un grupo extraño, que facilite el shock cultural y, por consiguiente, la emergencia de la conciencia de lo obvio, y/o una sólida formación en literatura acerca de otras culturas, tal como pone de manifiesto el siguiente texto de Wilcox:

[La etnografía es] un proceso continuado de investigación en el que hay que seguir ciertas normas antropológicas. Primera, intentar dejar a un lado las propias preconcepciones o estereotipos sobre lo que está ocurriendo y explorar el ámbito tal y como los participantes lo ven y lo construyen. Segunda, intentar convertir en extraño lo que es familiar, darse cuenta de que tanto el investigador como los

19 Con todo, hay antropólogos, como Davydd GrEENwoOD, "Estudiarnos a nosotros mismos: un problema falso y una ideología coercitiva", en AGUILAR, E. (coord.), De la construcción de la bistoria a la práctica de la antropología en España (Zaragoza: VII Congreso de Antropología Social, 1996), p. 153 y ss., que sostienen que los antropólogos comenzaron en EE.UU. por estudiar la propia sociedad, de modo que sólo más tarde se decantaron por la investigación fuera de sus fronteras.

20 Véase, v.g., GuASCH, Óscar, Observación participante (Madrid: CIS, 1997).

21 Un "método intelectual... que me gustaría llamar técnica del extrañamiento", tal como la definía Lévi-Strauss en 1973, según rememora Luis V. ABAD en La mirada distante sobre Lévi-Strauss (Madrid: CIS, 1995), p. 92. 
participantes dan muchas cosas por supuestas, de que eso que parece común es sin embargo extraordinario, y cuestionarse por qué existe o se lleva a cabo de esa forma, o por qué no es de otra manera (Erickson 1973, Spindler y Spindler 1982)... La experiencia directa en otras culturas, o al menos cierta familiaridad con la literatura transcultural, es muy útil para establecer las dos primeras características de la mentalidad etnográfica... ${ }^{22}$

Y en el mismo sentido se expresan Velasco, García Castaño y Díaz de Rada:

No es necesario un halo de exotismo para justificar una aproximación etnográfica. Pero sí lo es, como expone Wolcott, un cierto extrañamiento.. / Por último, y sólo con objeto de terminar esta lista de peculiaridades 'mayores' de la llamada investigación etnográfica.., una necesaria perspectiva transcultural debe presidir toda etnografía que pretenda alcanzar el objetivo de la interpretación.. Por una parte, poseer esa perspectiva intercultural llega a permitir, entre otras cosas, poner en cuestión lo que se observa o lo que se escucha.. (A)demás, en el momento en que ha de producirse la interpretación de los datos obtenidos éstos se entienden mejor a la luz de acontecimientos sobre temáticas similares en diferentes situaciones culturales../Y, como es lógico, para poder formularse uno a sí mismo tales preguntas [referidas a 'todo lo que ocurre a los que participan' de una realidad] debe pasar por el proceso de convertir en extraño lo familiar y cuestionárselo, de preguntarse y preguntar por las razones que lo justifican ${ }^{23}$.

Resulta curioso, por lo demás, que la metáfora con que Delgado y Gutiérrez ilustran su idea de que los observadores participantes no vemos las constricciones que nos impone nuestro método de observación ${ }^{24}$ sea la del pez proverbial de Kluckhohn, esto es, aquélla a la que los antropólogos (y sociólogos como Schutz, Hammersley, Taylor y Bogdan...) recurren para justificar su recomendación de convertir lo familiar en extraño:

22 Wilcox, "La etnografía como una metodología y su aplicación al estudio de la escuela: una revisión", en Velasco, H.; García Castaño, J. y díaz de Rada, A. (eds); Lecturas de antropología para educadores. El ámbito de la antropología de la educación y de la etnografía escolar (Madrid: Trotta, 1993 -1982-), pp. 96-97.

23 Velasco, H.; García Castaño, J. Y díaz de Rada, A., "Introducción", en Velasco, H.; García Castaño, J. Y Díaz DE RADA, A. (eds); Lecturas de antropología para educadores. El ámbito de la antropología de la educación y de la etnografía escolar (Madrid: Trotta, 1993), pp. 14 y 199.

24 "Es repetido que si nos hubiéramos desarrollado como especie humana bajo el mar, esta circunstancia sería probablemente lo último que llegaríamos a descubrir. De igual modo, las constricciones que impone a los análisis posibles la técnica del trabajo de campo y en concreto el rol de investigador participante (sea o no conocido como tal por los miembros del objeto de investigación) son lo último en ser descubierto como verdadera condición o presupuesto metodológico y epistemológico" (p. 145). 
Las personas más interesadas en hacerla [etnografía escolar] son, en su mayor parte, individuos que han pasado casi toda la vida en las escuelas - primero como alumnos, después como estudiantes del proceso escolar y finalmente como educadores profesionales-. Dada su entrega a la educación formal y su inmersión en ella, es tan probable que 'descubran' la cultura escolar como es que el pez proverbial de Kluckhohn descubra el agua ${ }^{25}$.

$\mathrm{Si}$ me he detenido en estas disquisiciones sobre el extrañamiento antropológico, ha sido - entre otras razones- porque su conceptualización como distanciamiento analítico ${ }^{26}$ tiene precisamente el objetivo de dotar de herramientas de vigilancia epistemológica a los etnógrafos que estudian en su propio grupo, a aquéllos que no son extranjeros con respecto a él, que no parten de una suficiente distancia cultural previa. Y ello es así debido, sobre todo, a que a partir de la década de los sesenta $-\mathrm{y}$ por razones que exponen, verbigracia, tanto Kaplan y Manners ${ }^{27}$ como Velasco ${ }^{28}$-, los antropólogos tuvieron que estudiar principalmente las sociedades occidentales y, en buena parte de las ocasiones, sus mismas sociedades. Es una situación de investigación que Spradley ${ }^{29}$ -para este último caso- denomina de "participación completa" y que constituye una de las modalidades en que se practica la observación participante. Si se echa un vistazo, por ejemplo, a las obras de etnógrafos españoles publicadas desde 1965, se puede comprobar que, salvo una minoría (que ha viajado, especialmente, a América Latina), casi todos han hecho trabajo de campo dentro de nuestras fronteras; lo mismo que ocurre en otros países caracterizados —en terminología de

25 WolcotT, Harry F., "Sobre la intención etnográfica", en Velasco, H.; García CASTAÑo, J. y DíAZ DE RADA, A. (Eds); Lecturas de antropología para educadores. El ámbito de la antropología de la educación y de la etnografía escolar (Madrid: Trotta, 1993 - 1985-), p. 139.

26 Se es extranjero con respecto a un campo de investigación (un grupo, una comunidad, una categoría social, el mundo de los artistas, de los antropólogos...); en cambio, lo que se 'extraña' analíticamente es el objeto de estudio, que - según la definición dada, por ejemplo, por HAMmERsLey y Atkinson [Etnografía. Métodos de investigación (Barcelona: Paidós, 1994)]— es un fenómeno (en esta ocasión social y/ o cultural) que se construye desde una determinada perspectiva teórica.

27 KAPLAN Y MANNERS, "Antropología en crisis: viejos temas y nuevas orientaciones", en José R. LloberA, La antropología como ciencia (Barcelona: Anagrama, 1975) [también en KAPLAN, D. y MANNERS, R.A., Introducción a la teoría antropológica (México: Nueva Imagen, $1979-1972-)$ ], pp. 330 y ss.

28 Velasco, H., "La antropología española como problema". Antropología, 3 (1992), pp. 120 y ss.

29 Op. cit., pp. 61 y ss. 
Velasco ${ }^{30}$ - por una antropología concéntrica ${ }^{31}$. Un caso paradigmático (por tratarse - según la cronología de Prat ${ }^{32}$ - de la primera etnografía sobre nuestro país, debida a un autóctono), es Belmonte de los Caballeros de Carmelo Lisón ${ }^{33}$, que delimita su investigación en el ámbito espacial de su comunidad de origen, cuyo verdadero nombre — siguiendo la costumbre de la época- oculta bajo aquel pseudónimo. Pero ¿qué decir del resto de los antropólogos (o sociólogos)?, ¿cuándo han sido extranjeros y cuándo nativos con respecto a sus campos de investigación? La distinción no es tan fácil de marcar como pudiera parecer a simple vista $y$, menos aun, si no se toma en cuenta el objeto que se pretende construir con la investigación. ¿A qué resoluciones habrían de llegar - por ejemplo- Rosario Otegui ${ }^{34}$ o Lourdes Segura ${ }^{35}$ si se pusieran a juzgar sus trabajos etnográficos: que han estudiado a su propio grupo, porque los sujetos que observaron eran españoles (en este caso, aragoneses), o a un grupo extraño, porque ninguna de ellas era originaria ni vivía en esa región?, ¿era Ana Rivas nativa cuando hizo trabajo de campo en Cantabria ${ }^{36}$ y extranjera cuando lo hizo en Aragón ${ }^{37}$ ?; ¿y qué decir de Lourdes Méndez ${ }^{38}$, una universitaria que ha investigado a las mujeres campesinas gallegas?, ¿y de Jordi Roca ${ }^{39}$ que ha publicado recientemente una investigación sobre la construcción del género femenino?: ¿ha estudiado lo extraño porque no es mujer, pero al mismo tiempo lo propio porque ha centrado su trabajo en Alcover, 'su pueblo'? Los diferentes niveles de la identidad cultural que Delgado y Gutiérrez ponen como

30 Op. cit., pp. 120 y ss.

31 Y no es necesario acudir tan sólo a la antropología española o de cualquier otro país 'periférico'; aunque en menor medida, ello es apreciable también en la etnografía (por ejemplo, escolar) de Estados Unidos y Gran Bretaña.

32 PRAT, J., Antropología y Etnología (Madrid: Universidad Complutense/Caja de Ahorros de Madrid, 1992).

33 Lisón, C., Belmonte de los Caballeros (Oxford: Oxford University Press, 1966).

34 OTEGUI, R., Estrategias e identidad. Un estudio antropológico sobre la provincia de Teruel (Teruel: Instituto de Estudios Turolenses, 1989).

35 SEgura, L., Identidad y Percusión (Zaragoza: CAI, 1986).

36 Rivas, A. M., Antropología social de Cantabria (Santander: Universidad de Cantabria, 1991).

37 RIVAS, A. M., Ritos, símbolos y valores en el análisis de la identidad en la provincia de Zaragoza (Zaragoza: CAI, 1986).

38 MÉndez, L., Cousa de mulleres. Campesinas, poder y vida cotidiana (Lugo 19401980) (Barcelona: Anthropos, 1988).

39 RocA, J., De la pureza a la maternidad. La construcción del género femenino en la postguerra española (Madrid: Publicaciones del Ministerio de Cultura, 1996). 
ilustración de la falta de homogeneidad en la cultura (niveles de identidad que, por otra parte, fueron los objetos de estudio de las nombradas Otegui, Segura y Rivas) se configuran como un hándicap a la hora de determinar con exactitud cuándo somos observadores exógenos y cuándo endógenos ${ }^{40}$. Es más, resulta desconcertante que los etnógrafos españoles, p.e., sean acusados por algunos de no establecer suficiente distancia con respecto a los problemas que investigan, porque se confunde la 'distancia viajada' con la 'distancia analítica', mientras que se ven incluídos entre los que se toman como dogma la extranjeridad por quienes no se preocupan por conocer cuál ha sido la evolución que ha experimentado la investigación etnográfica, cuáles son las características de las diversas tradiciones nacionales o no se molestan en distinguir entre las formas de practicarla, muchas veces condicionadas por las circunstancias específicas que se viven en cada situación y en cada lugar. Desde luego, ni en el librito de Rossi \& O’Higgins ${ }^{41}$, una breve introducción a la antropología escrita - además- por dos representantes de un país de antropología excéntrica, que es citado por Delgado y Gutiérrez inmediatamente después de presentar las "condiciones" de la observación participante, ni en Marcus \& Cushman ${ }^{42}$, Tyler ${ }^{43}$ o Tedlock ${ }^{44}$-mencionados más adelante-, cuyo interés se centra en la escritura y, de modo particular, en el género del "realismo etnográfico" de la antropología clásica británica, norteamericana y - en menor medida - francesa, se puede encontrar este tipo de especificaciones y matices necesarios para no dar una falsa imagen monolítica de la práctica y teorización antropológicas. Pero vamos a dejar este asunto, al menos por el momento, para seguir con las consideraciones sobre la estampa de la observación participante que nos ofrecen.

40 Está claro que no utilizo la misma concepción de endogenia/exogenia que Delgado y Gutiérrez, al menos en el sentido de que, a mi parecer, para caracterizar la endogenia es indiferente si la posición de observador se ejerce mientras se es actor o después de haberlo sido.

41 Rossi, I. y O'HIgGins, "Métodos antropológicos", en Teorias de la cultura y métodos antropológicos (Barcelona: Anagrama, 1981 -1980-).

42 Marcus, G. E. y Cushman, D. E., "Las etnografías como textos", en GeErTZ, C.; ClifFORD, J. et al., El surgimiento de la antropología postmoderna (Barcelona: Gedisa, 1991).

43 TYler, S., "Acerca de la 'descripción/desescritura' como un 'hablar por', en GEERTZ, C.; CLIFFORD, J. et al., El surgimiento de la antropologia posmoderna (Barcelona: Gedisa, 1991).

${ }^{44}$ TeDlock, D., "Preguntas concernientes a la antropología dialógica", en GeERTZ, C.; CluFForD, J. et al., El surgimiento de la antropología posmoderna (Barcelona: Gedisa, 1991 -1987-). 
"Ese sistema tiene una definición propia de sus fronteras", siguen aseverando, después de indicar algo a lo que - creo- ningún etnógrafo se opondría, aunque sólo sea porque lo de integramente se puede descifrar de muchas maneras: que "debe convivir íntegramente en el sistema a estudiar". Con respecto a aquella primera expresión, sin embargo, he de confesar que no estoy segura de saber interpretar correctamente su significado (no sé si debido a que no estoy iniciada en el lenguaje de la "cibernética de segundo orden") o, dicho con otras palabras, me veo obligada a recurrir a una traducción guiada casi exclusivamente por la intuición, que me induce a pensar - por un lado- que tal vez signifique que los sujetos que constituyen los grupos, las colectividades, las categorías o cualesquiera otros agrupamientos humanos estudiados (y concebidos como sistemas) por los etnógrafos cuentan con una idea de las lindes de tales grupos o agrupamientos (muchas veces objetivadas de los modos más diversos). Si es esto lo que se quiere decir, simplemente constatar que no se puede sino estar de acuerdo, pero que resulta difícil de valorar de qué manera constituye una condición específica de la observación participante. Ahora bien, por otro lado, también se puede querer notificar que los etnógrafos toman como fronteras de los sistemas que investigan aquéllas que son estipuladas por los propios integrantes de los mismos; lo que resulta bastante más discutible, puesto que ello va a depender de los presupuestos teórico-metodológicos de los que se parta y, en bastantes casos, las fronteras definidas desde dentro, más que configurar los límites del sistema investigado, se erigen en el objeto de la investigación, como sucede en la mayor parte de los trabajos etnográficos realizados en el campo de las identidades étnicas. La primera interpretación se ancla en el ámbito de la ontología (de cómo es la realidad social); la segunda, en cambio, en el de la metodología y, más concretamente, en el del cierre del campo de investigación. Por otra parte, lo más probable (por afirmaciones en esta dirección que hacen en la página 146) es que Delgado y Gutiérrez no se refieran a ninguna de estas dos cosas, y apunten a la manida figuración de que los etnógrafos siguen enzarzados en los tan traídos y llevados estudios de comunidad y/o de que la observación participante sólo es aplicable a los mismos ${ }^{45}$. De ser así, el riesgo de alejar-

45 (L)a presentación de un informe de investigación antropológica, denominada "una etnografía' (o una monografía etnográfica) está igualmente afectada por unas reglas de codificación. En primer lugar existe un determinado número de apartados temáticos acerca de los cuales el etnógrafo no debe dejar de proporcionar información (descripción del hábitat, actividades de la economía del grupo, ciclos estacionales, cultivos[...]). A continuación debe producir un informe con estilo descriptivo, buscando el mayor realismo y objetividad posible de sus descripciones, ocultando o 'retrasando' para un apartado final sus valoraciones y juicios personales, no utilizando la primera persona y buscando una posición narrativa de observador omnisciente (p. 146). 
se - aunque fuera momentáneamente- de figuras de apego como Marcus y Cushman, les sería recompensado con la oportunidad de hacer un recorrido propio por las etnografías publicadas, verbigracia, en los últimos 30 años, así como de comprobar que la mayoría de ellas (y no sólo las experimentales) no sólo no están afectadas por las "reglas de codificación" predicadas con respecto a aquéllos, sino - además- que buena parte de ellas no toman la comunidad, ya no sólo como unidad de análisis, sino ni siquiera como unidad de observación.

El mismo problema se me vuelve a aparecer de nuevo: no sé muy bien cómo entender la condición cuarta. ¿Qué quiere decir que la aintegración del analista será maximizada y funcionalm?, ¿y lo de que esto se debe lograr "sin dejar de ser por ello un analista externo"? Si se alude a que los observadores aspiran a participar (y una forma, aunque débil, de hacerlo consiste en estar presente) en las actividades de los sujetos investigados, con el fin - entre otras cosas- de tener una mejor posición para observar, y sin convertirse así en nativos..; en ese caso, no se podría tampoco más que aceptar la idea, excepto en lo que se refiere a la premisa omnipresente de que el observador participante no pertenece (o no debe pertenecer) al grupo investigado. Ahora bien, esta interpretación se viene abajo cuando, sólo un poco más adelante —en la misma página 144-, nos encontramos con la apreciación de una aparente contradicción entre tal estatuto de externo y un afán que - al parecer de los autores- embarga a cualquier observador participante:

Las epistemologías de los antropólogos culturales, o de otros investigadores desde la observación participante, consideran el relativismo cultural como una éti$\mathrm{Ca}^{46}$, y la función de distancia entre analista y nativo como un obstáculo o limitación que debe ser vencida mediante la integración del investigador en la comunidad de referencia. Pero esta terminología es engañosa. Pareciera indicar que aquéllos desean profundamente saltar esa barrera, suprimirla. ¿Por qué no, entonces, hacer una antropología de la cultura propia?

${ }^{46}$ Ha habido y hay antropólogos que consideran el relativismo como una ética, pero pretender que es algo intrínseco a "las epistemologías de los antropólogos culturales" hace sospechar - entre otras cosas- que no se tiene en cuenta, en primer lugar, el entramado de tesis diferentes (éticas, metodológicas y epistemológicas) que comprende el término de relativismo cultural; en segundo lugar, que el adscribirse, v.g., a la tesis metodológica (como acaece con la mayoría de los antropólogos) no obliga a aceptar las demás y, en tercer lugar, las - a veces- agrias discusiones habidas en el seno de la disciplina entre los partidarios de las tesis ética y/o epistemológica y sus detractores [ver KaPlan y MANNERS, op. cit., p. 25; LuQUE, E., Del conocimiento antropológico (Madrid: Siglo XXI-CIS, 1984), pp. 101 y ss.; GONZÁLEZ ECHEVARRía, A., La construcción teórica en antropología (Barcelona: Anthropos, 1987), pp. 179 y ss).]. 
A esta última pregunta considero que ya he contestado más arriba, y no voy a insistir más en ella. A la aparente contradicción de propósitos voy a dedicarme ahora, pues se origina - efectivamente- como consecuencia del uso de una terminología engañosa, de no distinguir conceptualmente entre diferentes clases de distancia, así como - y utilizo palabras de Llobera ${ }^{47}$ - de la creencia, no sometida a crítica, de que por el hecho de ser nativo se tiene un acceso especial al conocimiento de la sociedad de la que uno es miembro. Paul Bohannan, en un manual de introducción a la antropología que titula Para raros, nosotros ${ }^{48}$, afirma que "(e)l estatuto de ajeno es un punto esencial, no necesariamente un inconveniente que superar. ¿Acaso es una excepción en el mundo de los antropólogos y no está interesado, como Delgado y Gutiérrez predican de los demás, en saltar la barrera o distancia entre analista y nativos? Ocurre, sin embargo, que éstos no discriminan —en el artículo que nos ocu$\mathrm{pa}$ - entre las diversas acepciones con que se emplea en antropología el vocablo distancia, y no se les puede reprochar que no lo hagan porque muchos antropólogos las confunden con excesiva frecuencia, originándose por esa causa más de una polémica estéril dentro del gremio, por no tildarlas —en ciertos casos- de auténticos diálogos de besugo. Un rápido repaso por algunas obras antropológicas permite detectar, al menos, seis sentidos del término distancia, a veces presentes (todos o casi todos) en una sola de ellas. Unos significados que -asumiendo el riesgo que implica la polisemia de cualquier nominación y reconociendo de antemano que están relacionados entre sí, a veces, de forma muy compleja - voy a intentar identificar con los términos de 'distancia viajada' (que tomo de Greenwood ${ }^{49}$ ), 'distancia observacional' (no-participación), 'distancia social', 'distancia cultural', 'distancia afectiva' y 'distancia analítica'. Ahora bien, para ello, voy a abandonar un rato la obra de Delgado y Gutiérrez, reproduciendo a continuación un párrafo procedente de un libro de Óscar Guasch sobre La Observación Participante y, en esta ocasión, del capítulo que intitula "La distancia social" ${ }^{50}$ :

47 Llobera, J. R., La identidad de la Antropología (Barcelona: Anagrama, 1990), p. 118.

48 Bohannan, P., Para raros, nosotros (Madrid: Akal, 1996 - 1992-), p. 35.

49 GREENwoOD, D., "Estudiarnos a nosotros mismos: un problema falso y una ideología coercitivan, en AGUilaR, E. (coord.), De la construcción de la bistoria a la práctica de la antropología en España (Zaragoza: VII Congreso de Antropología Social, 1996), p. 155.

50 GUASCH, Óscar, Observación participante (Madrid: CIS, 1997), pp. 15-33. 
Negar la distancia cultural respecto al objeto de estudio (tal y como sucede en las antropologías periféricas que no mimetizan los modelos hegemónicos) implica diversos problemas, pero también permite obviar otros. Negar la distancia cultural pone en cuestión el rito de paso profesional ${ }^{51}$, y difumina las fronteras interdisciplinares y profesionales, en particular respecto a la Sociología y los soció$\operatorname{logos}{ }^{52}$. En segundo lugar, la ausencia de distancia, viene a negar el yo testifical construido en torno al sindrome de haber estado alli ${ }^{53}$. La autoridad del etnógrafo queda cuestionada porque la investigación sobre el propio contexto social y cultural puede realizarla cualquiera: incluso el llamado periodismo de investigación ${ }^{54}$. Resulta evidente que la necesidad de la distancia respecto al objeto de es-

51 ¿De qué forma lo consigue? Si el trabajo de campo es el "rito de paso profesional" en antropología, los antropólogos 'periféricos' lo han seguido pasando en la misma medida que los antropólogos 'hegemónicos', si no en sociedades exóticas, sí en las de su propio país.

52 Los que piensan que las fronteras disciplinares se trazan a partir de cómo se construye el objeto de estudio, y no a través de diferencias entre los campos (geográficos, por ejemplo) en que se investiga, hace tiempo que dudan que alguna vez haya habido fronteras precisas y/o impermeables entre ambas disciplinas, incluso en la tan zarandeada época de la antropología clásica. Baste recordar que RADCLIFFEBROWN [Estructura y función en la sociedad primitiva (Barcelona: Planeta-Agostini, 1986 - 1952-)], por ejemplo, consideraba que la antropología (al igual que la sociología) formaba parte de una macrodisciplina que él llamaba Sociología Comparada.

53 ¿No se puede construir también en torno al sindrome de haber estado aqui?, ¿no se puede escribir etnografía confesional cuando se estudia la propia sociedad? Si Guasch toma el concepto de yo-testifical de GeERTz [que le dedica un capítulo entero de El antropólogo como autor (pp. 83-110)], no resulta clara la forma en que la disminución o la anulación de la distancia (sea ésta la que sea) puede negar el yo testifical, dado que el antropólogo norteamericano lo presenta como un estilo de escritura etnográfica: “O, por decirlo rápidamente de otra manera, antes de que la psicología pueda colarse de rondón, se trata de ver cómo introducir un autor yo-testifical en una historia dedicada a pintar a otros. Comprometerse con una concepción esencialmente biográfica del 'estar allí', antes que con una de tipo reflexivo, aventurero u observacional, es comprometerse con un enfoque confesional de la construcción textual. La persona real que Lévi-Strauss, Evans-Pritchard y Malinowski han intentado confinar en sus fabulaciones, memorias o ensoñaciones, ese yo creatural que ha llevado a cabo cosas extrañas y sufrido otras no menos raras, fluye ahora hacia el interior mismo de la obra" (p. 94). Si Geertz relaciona el yo-testifical con el "estar allí, es porque lo atribuye al tipo de narración elaborada por algunos etnógrafos influidos por el Malinowski del Diary, que -efectivamente- habían estado allí y cuyos otros todavía lo estaban.

54 Si lo que cuestiona la autoridad del etnógrafo es que otros puedan realizar también la investigación, esa autoridad queda cuestionada haya o no 'distancia viajada', porque esos otros (y principalmente los periodistas) tienen tanta o mayor facilidad que él no sólo para 'estar aquí', sino también para 'estar allí'. Por otro lado, desde mi punto de vista, esa posibilidad de realizar también la investigación no pone en cues- 
tudio que tanto defiende el modelo etnográfico clásico, tiene que ver más con la profesionalización y la academización de la Antropología que con cuestiones epistemológicas relevantes. Sin embargo, son muchos los problemas que pueden obviarse estando aqui; en especial que no existen problemas de traducción cultural. Informante, investigador y lector comparten un mínimo de intersubjetividad que hace innecesaria la tarea de traducción cultural. Estando aqui, la interpretación de la realidad social que surge de la observación participante se construye a partir de ciertos códigos compartidos, aun cuando los sesgos personales persistan en quien informa, en quien investiga y quien lee. Con todo, incluso estando aqui (y como consecuencia de la acrítica transposición del modelo etnográfico clásico a las sociedades complejas), se intenta construir la distancia de manera artificial: primitivizando las comunidades rurales o buscando grupos marginales en nuestra sociedad ${ }^{55}$. La aldea global impide incluso esta construcción artificial de la distancia. Es casi imposible estar alli $i^{56} 57$

En la cita precedente se pueden encontrar al menos dos acepciones otorgadas a la palabra distancia. Por un lado, la que he denominado 'distancia viajada' que, generalmente, se concibe como una distancia geográfico-política, es decir, aquélla que - en España, para poner un ejemplose establecería cuando el investigador estudia en un espacio que no es su país-Estado, su país-Comunidad Autónoma o, si seguimos con la lógica de

tión por sí sola ningún trabajo antropológico o de cualquier otra clase, sino que aumenta las oportunidades de se haga, lo que - desde luego- no es lo mismo.

55 En primer lugar, está por saber si la defensa de la distancia es fruto de "una acrítica trasposición del modelo etnográfico clásico" o, por el contrario, de una actitud crítica frente a quienes parecen pensar - acudiendo de nuevo a la expresión de Llobera- que "tienen un acceso privilegiado a su propia cultura" a pesar de que expresamente reconozcan que la proximidad implica diversos problemas que, por cierto, apenas mencionan. En segundo lugar, desconcierta ese cambio brusco de campos semánticos a que el autor nos somete dentro de esta frase: si "estar allí" / "estar aquí" se estaba planteando como una distinción entre estudiar una sociedad ajena o la propia, no se comprende por qué - de repente- se presenta como una distinción entre estudiar sociedades simples o sociedades complejas [un etnógrafo español que investigara, v.g., en la ciudad de Calcuta 'estaría allí, pero no por ello se estaría encarando a una sociedad simple, al menos no más simple que la de Madrid].

56 Si la existencia de la llamada aldea global, entendida en términos culturales, "hace casi imposible estar allí, también haría casi imposible estar aquí, porque todo sería 'casi' lo mismo. Por otro lado, si fuera verdad que existe algo que pudiera equipararse - en aquellos términos - a la idea de aldea global, todas las ventajas que Guasch atribuye a los estudios realizados en un espacio geográfico que se tildara de "aquín serían igualmente aplicables a los efectuados "allín: "En la aldea global ya sólo existe una cultura (en trance de ser hegemónica) que interactuando con configuraciones culturales geográficamente delimitadas, genera intersubjetividades con características específicas" (GuAsch, op. cit., p. 29).

57 GUASCH, op. cit., pp. 28-29. 
la segmentación territorial, su ciudad o pueblo; una 'distancia viajada' cuyo incremento no siempre se corresponde con un aumento de lo que llamaré 'distancia cultural', considerada como diferencias en las categorías cognitivas, intereses, prácticas sociales, etc ${ }^{58}$. Es el sentido de 'distancia viajada' y no el de 'distancia cultural' el que adquiere este último término cuando es tomado por Guasch para asegurar que "(n)egar la distancia cultural... difumina las fronteras interdisciplinares y profesionales, en particular respecto a la Sociología y los sociólogos"; por lo menos es el que permite entender en qué puede consistir esa difuminación. Los sociólogos no suelen hacer (aunque también los hay que hacen) investigaciones muy 'viajadas', es decir, fuera de las fronteras de su país-Estado, lo que no significa que siempre las lleven a cabo dentro de los grupos en que participan como actores ordinarios o estudiando categorías de personas a las que pertenecen ${ }^{59}$, es decir, investigan con frecuencia en contextos que presentan diferencias culturales (o, si se quiere, subculturales). Como he manifestado más arriba, la 'distancia cultural' no concuerda necesariamente con la 'distancia viajada': quien autodefiniéndose como española, mujer y heterosexual se anima a llevar a cabo trabajo de campo en ambientes gays de Madrid para estudiar las relaciones de pareja (como fue el caso de quien esto escribe ${ }^{60}$ ) es probable que aprecie mayor 'distancia cultural' con respecto a las concepciones y las prácticas ligadas a ese tema que tienen los homosexuales ${ }^{61}$, que con relación a las creencias y prácticas religiosas de los quechuas y aymaras de una ciudad boliviana como Oruro (que tuve la ocasión de conocer bastantes años después).

En el transcurso de la argumentación que desarrolla Guasch se puede detectar asimismo, aunque enredado con el de 'distancia viajada', el signi-

58 No obstante, la máxima de 'un país, una cultura' sigue pesando aun en muchas mentes.

59 Ver a este respecto las obras de WHYTE [La sociedad de las esquinas (México: Diana, 1971)] o GoffmAN [Internados (Buenos Aires: Amorrortu, 1981)], dos clásicos de la etnografía sociológica citados por Guasch.

6) Y de otros estudiantes de sociología que, motivados por la experiencia previa (en 1977) de un estudio realizado mediante la observación de nuestro comportamiento en grupo, nos constituimos en equipo estable de investigación $\mathrm{y}$, además de la indicada sobre las relaciones de pareja entre los homosexuales (efectuada con observación participante y entrevistas), llevamos a cabo otras sobre la sexualidad en las mujeres (con reuniones de grupo, como entonces se llamaban), los equipamientos de Móstoles, etc. Dentro del equipo estaban, entre otros, Manuel López del Rey, Manuel Malaña, Rosa Ortega y Elena Macazaga.

61 No cuando se trataba otros asuntos, no relacionados directamente con la investigación, como el del panorama político español del momento. 
ficado de 'distancia cultural' que he propuesto hace un momento. Tal es así cuando afirma que "(e)stando aquí, la interpretación de la realidad social que surge de la observación participante se construye a partir de ciertos códigos compartidos. El de 'distancia analítica' (ya establecido al hablar del extrañamiento antropológico) no aparece, sin embargo, ni en los párrafos comentados ni en el resto de la obra (si no es indirectamente, a través de ciertas referencias bibliográficas a Taylor y Bogdan, verbigracia), toda vez que no se puede considerar equivalente a la idea que Guasch tiene de "construir la distancia de manera artificial", como se puede comprobar si se cotejan ambas nociones. Con todo, se hallan otras acepciones de 'distancia' conforme nos adentramos en la lectura:

El fin último de la observación participante es anular, disminuir o (al menos) controlar mediante la inmersión en un contexto social ajeno ${ }^{62}$ la distancia social que existe entre el observador y los observados ${ }^{63}$, precisamente para captar su punto de vista. Pero en función de esa distancia inicial, la posibilidad de conseguir penetrar la realidad estudiada es mayor o menor. Ser estadounidense negro, ser asiático, o ser gay, puede ser importante si quien investiga va a observar blancos, europeos o heterosexuales respectivamente../ Existen prevenciones por parte de los científicos sociales respecto de la falta de distancia en el campo. La etnografía clásica definida por las antropologías hegemónicas se construye precisamente en torno al mito de la distancia en el campo. También la sociología defiende 'que los investigadores se abstengan de estudiar escenarios en los cuales tengan una directa participación personal o profesional (Taylor y Bogdan 1992: 36 ), con el argumento de que la proximidad dificulta la perspectiva crítica ${ }^{64}$. En

62 ¿Desde qué perspectiva es considerado aquí ajeno? Vuelven a surgir siempre los mismos interrogantes cuando se aborda esta cuestión sin que se expliciten los criterios utilizados en cada caso.

63 En mi opinión, "el fin último" de la observación participante, como de cualquier otra técnica o "estrategia de investigación" social (como denomina Guasch a la observación participante), consiste en acercarse al conocimiento (siempre provisional) de una determina realidad o de las prácticas socioculturales, de las que forman parte los puntos de vista de los observados. La "inmersión en un determinado contexto social" es la estrategia, entre otras, que adopta el observador participante a la hora de intentar conseguirlo.

64 Esa cita de Taylor y Bogdan (que yo encuentro en la edición de 1986) comienza así: "Recomendamos que los investigadores se abstengan...". Es decir, que se trata de una recomendación, y no de una negación del valor que pueda tener cualquier investigación endógena. De hecho, se completa con una nota a pie de página, la número 3, donde se reconoce que hay "estudios destacados" llevados a cabo por "personas que fueron participantes de los escenarios que observaron". Así y todo, se continúa diciendo: "es preferible no estar íntimamente ligado al objeto de estudio, en particular si no se tiene experiencia en la observación participante. Cuanto más próximo se está a algo, más difícil resulta desarrollar la perspectiva crítica necesaria para con- 
el presente manual se defiende lo contrario. Es la proximidad al fenómeno investigado lo que facilita el acceso al campo y a los escenarios ${ }^{65}$. No tiene demasiado sentido empecinarse en convertir lo fácil en difícil. En el fondo, el discurso sobre la distancia es un intento de mantener la neutralidad política, no tanto en las relaciones sociales que mantiene quien observa con los observados, como en las relaciones que los observados mantienen con la sociedad ${ }^{66}$. Convertirse en un miembro, o ser un miembro, se entiende como algo peligroso.../Ante el uso frecuente de la observación participante para abordar situaciones sociales de colonización o de desviación social, la búsqueda de la distancia pretende, en realidad, neutralizar la implicación política del investigador en el sentido de tomar partido por los observados.. /La distancia, social, espacial o cultural, no garantiza que quien investiga sea hábil y sutil en la observación ${ }^{67} 68$.

En esta ocasión, toda la crítica de Guasch a la distancia propugnada tanto por los antropólogos como por los sociólogos que han teorizado sobre la observación participante se fundamenta en la idea de que aquélla dificulta el "acceso al campo y a los escenarios", que buscarla o construirla no es más que empeñarse en "convertir lo fácil en difícil...., atribuyendo de paso cierta pusilanimidad política a quienes la defienden, lo que induce a ver al etnógrafo que desafía la regla como un personaje heroico, como un Robin Hood de los desamparados, colonizados o desviados sociales. $\mathrm{O}$, dicho de otro modo, lo que yo intento discriminar conceptualmente con los nombres de 'distancia observacional', 'distancia analítica' y 'distancia afectiva' se presentan como una y la misma cosa. Ahora bien, la 'distancia analítica' no tiene como razón de ser el facilitar u obstaculizar el acceso al campo y/o a los escenarios, entre otras razones, porque se sitúa como una operación epistemológica (no como un tipo de relación social con los sujetos investigados), como una forma de pro-

ducir una investigación consistente" [TAYLOR, S. y BOGDAN, R., Introducción a los métodos cualitativos de investigación (Buenos Aires: Paidós, 1986) , p. 36].

65 Pero esto supone (como se verá después) ubicar el plano de la discusión en un terreno distinto a como lo hacen, por ejemplo, los citados Taylor y Bogdan, por cuanto ellos - en las palabras traídas a colación por Guasch - no se refieren al tema del acceso al campo y/o los escenarios, sino al de las categorías con que se enfrenta el objeto de estudio, lo que ellos denominan "la perspectiva crítica necesaria para conducir una investigación consistente.

66 Greenwood, en el artículo citado más atrás, plantea la tesis de que fueron razones políticas las que explican que la antropología, en esta ocasión la norteamericana, pasara de realizar estudios en la propia sociedad y, más en concreto, entre sus sectores más marginados, a realizarlos en sociedades exóticas. ¿Alude Guasch a esto mismo con las palabras que deja en el aire?

67 Como tampoco la ausencia de 'distancia'.

68 GuASCH, op. cit., pp. 35-46. 
ducir la "ruptura" (en la nomenclatura de Bourdieu, Chamboredon y Passeron ${ }^{69}$ ) necesaria cuando el investigador se embarca en la "construcción" del objeto de estudio. La 'distancia analítica' es un concepto que no alude a cómo hay que relacionarse con los agentes sociales ni a recetas metodológicas como la que estipula que el etnógrafo tiene que mostrarse frente a ellos (a través de sus preguntas, por ejemplo) como un ignorante ingenuo ${ }^{70}$ - según la han interpretado otros-, sino a la vigilancia que debe ejercer sobre las categorías que vierte en la producción/análisis de su objeto de estudio, así como sobre las cegueras que le dificultan captar lo obvio, lo evidente, tal como se ha señalado más atrás. Los dos significados de distancia que se vinculan directamente con el acceso al campo y a los escenarios" son, desde mi perspectiva, los que he calificado de 'distancia observacional' y 'distancia social', aunque cada una lo haga de distinta manera. Así, 'la distancia observacional' sería la que se da en las situaciones en que el etnógrafo no participa en la vida cotidiana y/o no interactúa con los sujetos investigados, sino es incidental y mínimamente. Es la que caracteriza a dos de las modalidades de observación que forman parte de la ya mencionada clasificación de Spradley: la "no participación" y la "participación pasiva", y que los etnógrafos adoptan en determinadas fases de sus investigaciones, en función - v.g.- de las estrategias de acceso a los escenarios que adoptan y/o de lo que desean observar en cada momento. No obstante, si algo imprime carácter al trabajo de campo del etnógrafo (y, por ende, a su técnica emblemática, la observación participante) es su empeño en reducir lo máximo posible esa 'distancia observacional', no quedarse en ella, esto es, conseguir el acceso al campo, a los escenarios y/o a cierta información (generalmente, no pública o semipública) adoptando roles socialmente aceptables que le permitan la participación ${ }^{71}$. Este sentido de 'distancia observacional' es el que

69 Bourdieu, P.; Chamboredon, J. C. y Passeron, J.C., El oficio de sociólogo (Madrid: Siglo XIX, 1976).

${ }^{70}$ Lo que se refiere igualmente al acceso; en este caso, al acceso a ciertos tipos de información. Ahora bien, la validez de esta receta dependerá de los contextos y de las características de los sujetos investigados.

71 Esos papeles puede tenerlos ya el investigador si, por ejemplo, es actor del campo en que se investiga; lo que no quita para que, para acceder a determinados escenarios y/o información, no tenga también que negociar el acceso como le ocurre a un etnógrafo exógeno. No quiero cerrar esta nota sin reproducir un nuevo fragmento del texto de Delgado y Gutiérrez: "Es preciso asumir la tácita obligación de ser un extranjero (o lo más extranjero posible) respecto al grupo humano,.. y participar activamente en su vida cotidiana (generalmente adoptando funciones de maestro, médico, transportista, etc.)..." [p. 145]. Esta lista de funciones — dos de las cuales son 
descubro, no sé si acertadamente, en Guasch cuando manifiesta opiniones como las que he introducido al inicio de este párrafo.

En cuanto a 'la distancia social', estoy reconociendo como tal la que se establece entre los individuos y los grupos como consecuencia de presentar un conjunto de comportamientos, prácticas (verbales y no verbales), signos (en el vestido, los gestos, el aspecto fenotípico...), etc., que son percibidos recíprocamente como distinciones de status, raza, etnia, edad, género, nacionalidad, religión... o credo político. Así entendida, 'la distancia social' puede constituir una traba para que el etnógrafo logre el acceso, como se encarga de poner de manifiesto Guasch: "Ser estadounidense negro, ser asiático, o ser gay, puede ser importante si quien investiga va a observar blancos, europeos o heterosexuales respectivamente". En otro orden de cosas, es cierto que lo social constituye la base sobre la que se edifica lo cultural, pues no en vano las formas de percibir, sentir y actuar - como recuerda Bourdieu ${ }^{72}$ - dependen de la historia interiorizada e incorporada por los individuos según las posiciones que ocupan en la estructura social; del mismo modo que, a la inversa, 'la distancia cultural' conforma la base sobre la que los agentes sociales elaboran 'la distancia social'. No obstante, he estimado conveniente distinguirlas, puesto que ello permite discriminar entre dos cuestiones que se presentan en la investigación etnográfica: por un lado, que las características sociales del investigador (sin olvidar, empero, sus habilidades de negociación) tienen un papel importante en la consecución del acceso y, por otro, que se enfrenta a 'los otros' (sean éstos quienes sean) desde categorías culturales que, si no son sometidas a vigilancia epistemológica, estarán tácita e imperceptiblemente mediando en su percepción, sentimientos y actuación, en lo que observa y no-observa. Desde luego, la 'distancia analítica' no es garantía de que esa mediación no se vaya a producir (¿acaso es posible?), pero sí posibilitará, en buena medida, que se haga explícita y pue-

las resaltadas, p.e., por Barley en El antropólogo inocente (Barcelona: Anagrama, 1993 -1986-) con relación a su experiencia de campo en Camerún - resulta bastante magra si se compara con la que podría darse de las que habitualmente desempeña un antropólogo que investiga, v.g., en España: conferenciante en Semanas Culturales municipales y en Jornadas organizadas por ciertas asociaciones, compañero de tertulia de determinadas personas, integrante de una 'colla' o una 'cuadrilla' de amigos, 'voluntario' en la vendimia, en la recogida de espárragos, de aceitunas o de almendras, colaborador en la puesta en marcha de una cooperativa industrial o en la ornamentación festera de calles, cuidador de niños y cocinero cuando alguna anfitriona trabaja fuera de casa, camarero en una discoteca, ayudante de trabajadoras sociales, amanuense y asesor en reclamaciones a la administración pública, etc., etc., etc.

72 Bourdieu, P., El sentido práctico (Madrid: Taurus, 1991 -1980-). 
da ser sometida a crítica. Si por mantener esto merezco ser tildada de positivista $\mathrm{o}$, según quien juzgue, de postpositivista, me resignaré a cargar - afortunadamente no sola - con el lastre de la etiqueta.

Después de haber intentado mostrar algunas interrelaciones entre las diferentes nociones de distancia, aunque haya sido rápidamente y dejando de lado buena parte de su complejidad, voy a acercarme, por último, a lo que he convenido en nominar 'distancia afectiva'. Antes que nada, quisiera declarar mi convencimiento de que la implicación afectiva con los agentes estudiados es algo no sé si peligroso, pero sí inevitable, y el grado en que el etnógrafo se deje llevar por sus afectos y/o desafectos constituye una cuestión de ética - y estética- personal, lo mismo que el grado en que unos u otros intervengan en su compromiso político ya sea con la causa de los investigados (que no siempre son colonizados o desviados sociales ni es forzoso que lo sean) o con su contra-causa. Es más, en principio, esos afectos o desafectos no tienen por qué mermar la calidad de la investigación etnográfica, entre otros motivos, porque no están reñidos con la adopción de una postura de 'distancia analítica' ni con la aplicación de modelos de análisis adecuados a la naturaleza de los fenómenos o prácticas estudiadas. Desde este punto de vista, "el discurso sobre la distancia" no sólo no es un intento de "mantener la neutralidad polítican, sino que puede constituir una potente arma en ese ámbito:

El sociólogo [yo añado el antropólogo] está tanto mejor armado para descubrir lo oculto cuanto mejor armado esté científicamente, cuanto mejor utilice el capital de conceptos, métodos y técnicas que han acumulado sus predecesores.. y cuanto más 'crítico' sea, cuanto más subversiva sea la intención consciente o inconsciente que lo anima, y más interés tenga por revelar lo que está censurado, reprimido, en el mundo social. Si la sociología no avanza con mayor rapidez, al igual que la ciencia social en general, ello se debe quizá en parte al hecho de que estos dos factores tienden a variar en razón inversa ${ }^{73}$.

Pero regresemos, tras este largo excursus, al punto del texto de Delgado y Gutiérrez en que nos habíamos quedado, a la condición quinta, que reza así: "El investigador debe escribir una monografía empleando el género del 'realismo etnográfico'. Nos topamos nuevamente con uno de los rasgos con que los postmodernos peculiarizan la etnografía clásica, no toda la práctica de la observación participante. De hecho, algunos de los antropólogos que se autoproclaman miembros de esa corriente de pensa-

73 Bourdieu, P., "Una ciencia que incomoda", en Sociología y Cultura (México: Grijalbo, 1990 - $1980-)$, p. 82. 
miento, basándose en una experiencia de observación participante, han escrito etnografías que han sido presentadas (amen de otras anteriores -y a parecidas características literarias responden también otras posteriores-) como alternativas al realismo etnográfico (Bahr, Gregorio, López y Álvarez ${ }^{74}$, Rabinow ${ }^{75}$, Dumont ${ }^{76}$, Rosaldo ${ }^{77}$, Taussing ${ }^{78}$..). Entonces, de aceptar las premisas y la lógica que Delgado y Gutiérrez nos brindan ¿a qué conclusiones hemos de llegar?, ¿a que, dado que estas y otras monografías no responden al género realista $\mathrm{y}$, por consiguiente, incumplen - al menos- una de las condiciones, ya no se pude decir que su metodología ha recurrido a la observación participante o, por el contrario, hemos de deducir que el realismo etnográfico no es una condición de la observación participante? ${ }^{79} \mathrm{Y}$ parecidos interrogantes surgen inevitablemente cuando se aborda la condición sexta. Pero no nos precipitemos con el desenlace de la historia sin antes desenmarañar lo que esta última nos insinúa: ¿de dónde sacan Delgado y Gutiérrez que el etnógrafo "debe dar por finalizada la circulación del texto y la interpretación con la monografía dirigida a la comunidad académica" o que su "siguiente paso textual, en todo caso, estará constituido por la construcción teóricaw? En lo que atañe a la primera parte de la cuestión, es preciso constatar que Marcus y Cushman ${ }^{80}$, por ejemplo, presentan el tema del público al que se dirigen las monografías de un modo bastante más matizado. No hablan de "Comunidad académica" sin más, sino que plantean la diferente manera en que se escribe etnografía según sea el lectorado en el que se está pensando: “los especialistas en el área, que posee la mayor familiaridad con la temática del texto", "el lectorado antropológico general", "el de otras ciencias sociales", "el de los estudiantes", "el orientado hacia la acción, consistente en funcionarios del gobierno, administradores de programas... y el ulectorado popular, que mira a la etnografía por su mensaje o su

74 Bahr, D. M.; Gregorio, J.; López, D. I. y Álvarez, A., Priman Shamanism and Staying Sickness (Tucson: University of Arizona Press, 1974).

75 RaBINOW, Paul, Reflexiones sobre el trabajo de campo en Marruecos (Madrid-Gijón: Júcar, 1992 -1977-).

76 Dumont, Jean-Paul, The Headman and I (Austin: University Texas Press, 1978).

77 Rosaldo, Ilongot Headbunting 1.883-1974: A Study in Society and History (Stanford: Stanford University Press, 1980).

78 Taussing, M. T., The Devil and Commodity Fetishism in South America (Chapel Hill: University of North Carolina Press, 1980).

79 También cabe otra posibilidad, aunque suene aberrante: incluir esas obras dentro del 'realismo etnográfico'.

80 Op. cit., pp. 197 y ss. 
verdad ${ }^{81}$. De todos ellos, sólo los tres primeros y tal vez el cuarto forman parte de la "comunidad académica", y - agregaría que- de comunidades académicas diferentes ${ }^{82}$. Bien es probable que, en realidad, Delgado y Gutiérrez pueden estar refiriéndose menos a esto (no lo aclaran, sin embargo), que al hecho de que los antropólogos, mayoritariamente, dejen de hacer etnografía cuando han publicado obras que -independientemente del público para el que estén escritas- han sido aceptadas por la comunidad antropológica y, por tanto, les han permitido adquirir prestigio (y/o una titularidad o cátedra, ¿por qué no decirlo?) dentro de la misma; no interesándose, por consiguiente, en otras posibles utilizaciones de los resultados de sus investigaciones, tal como parece suceder, en cambio, con los que practican las metodologías de Investigación-Acción o de Investigación-Acción-Participativa. Nada que objetar a estas posibles imputaciones, salvo comentar que no sólo los etnógrafos que hacen uso de la observación participante, sino la mayoría de los investigadores sociales vinculados a departamentos universitarios - ya hayan recurrido a la encuesta, a los grupos de discusión, a las entrevistas semiestructuradas, al análisis de redes y/o a la simple revisión bibliográfica- han cojeado del mismo pie, por lo que vuelvo a tener dificultades a la hora de ver su especial vinculación con la observación participante. Encuentro -no sé si con razón- que esa orientación academicista de las obras etnográficas se halla más ligada al escaso desarrollo (salvo en países como EE.UU.) de lo que se viene conociendo como antropología aplicada y a las pocas, por no decir nulas, salidas profesionales que tiene hoy en día un antropólogo fuera de los muros universitarios, que al hecho de apelar a una técnica o a una metodología determinadas, puesto que considero — no quiero creer

81 Resulta extraño que Delgado y Gutiérrez, conociendo los planteamientos que Marcus \& Cushman desarrollan en el artículo al que aludo (de hecho, en la página 147 , exponen una reseña referida a los grupos de lectores que estos últimos establecen, si bien dentro de un campo de discusión distinto), no hayan caído en la cuenta de su excesiva simplificación del tema.

82 La mayor parte de las monografías de Margaret MEAD [Adolescencia, sexo $y$ cultura en Samoa (Barcelona: Laia, 1972 -1928-), Sexo y temperamento en las sociedades primitivas (Barcelona: Laia, 1973 -1935-), etc.] por ejemplo, o las obras cuasimonográficas y muy conocidas de BARLEY [El antropólogo inocente, ya citada, o Una plaga de orugas (Barcelona: Anagrama, 1993 -1986-)], no están dirigidas a la comunidad antropológica, al menos no exclusivamente, lo que no quita para que otras de estos mismos autores estén orientadas principalmente a ella. Que el gran público llegue o no a esta clase de escrituras es una cuestión de habilidad con la pluma o de estrategias de marketing que poco tiene que ver a veces con las intenciones del etnógrafo. 
que ingenuamente- que es ésta la que se adapta (o, al menos, se tendría que adaptar) a las circunstancias concretas de investigación ${ }^{83}$.

Por lo que atañe a la coletilla con que se expone la sexta y última condición («el siguiente paso textual, en todo caso, estará constituido por la construcción teórican), es una afirmación que encierra dos supuestos de los que ya he tenido la oportunidad de ocuparme en otro sitio ${ }^{84}$ : que la investigación etnográfica (con observación participante) consiste en la mera recopilación de datos, de suerte que la monografía etnográfica sería la 'descripción' - además - de una sola cultura; y, por otro lado, que la comparación dirigida a las generalizaciones, teóricas se realiza en una fase posterior, llamada por algunos etnológica o antropológica. Es decir, que adoptar como propio el juicio de que la construcción teórica es un "siguiente paso textual" revela, en primer lugar, que se comparte una visión temporalmente estratificada - y más que discutible - de la construcción teórica en antropología y, en segundo lugar, que se sigue acríticamente ciertas visiones de la etnografía (divulgadas, por ejemplo, por antropólogos como Llobera ${ }^{85}$ ), sin haberse parado antes a comprobar si esos planteamientos se mantienen una vez revisadas las obras aludidas ${ }^{86}$. Sugerir tan

83 Así y todo, no faltan ejemplos de otras utilizaciones de las investigaciones antropológicas que, empero, tampoco excluyen aquélla. En España, verbigracia, se han realizado o se están realizando, al menos, dos basadas en la I-A-P, una llevada a cabo por GREENWOOD Y GONZÁLEZ en las cooperativas de Mondragón [Culturas de Fagor: Estudio antropológico de las cooperativas de Mondragón (San Sebastián: Txertoa, 1990)] y otra por ESCALERA Y RUIZ en las minas de Río Tinto ["De ser obrero a ser empresario'. I.A.P. para la viabilidad socio-técnica de minas de Río Tinto", en PAlEnzuela, Pablo (coord.), Antropología del Trabajo (Zaragoza: VII Congreso de Antropología Social, 1996)]. Y otro antropólogo español, Ángel MONTES DEL CASTILLO, trasladó el mismo tipo de experiencia a Pucará -Ecuador- [Simbolismo y poder (Barcelona: Anthropos, 1989)]. Por otro lado, ¿excluye la metodología de la I-A-P la observación participante o los grupos de discusión, p.e., si se conciben como técnicas y no como paradigmas de investigación?

84 Jociles, M. I., "Nigel Barley y la investigación etnográfica". Política y Sociedad, n. ${ }^{\circ} 24$ (1997), pp. 111-112.

85 LlOBERA, op. cit., pp. 23 y ss. Digo Llobera, y no Lévi-Strauss, porque la distinción que este último establece entre etnografía, etnología y antropología se basa en las diferencias tanto del grado de abstracción de la teoría como del ámbito (temporal, geográfico o temático) al que se puede considerar aplicable, y no en la presencia/ ausencia de la misma.

86 ¿Que cuáles son, por cierto, las que aducen para sostener su posicionamiento? La falta de apoyatura empírica utilizada por Delgado y Gutiérrez para fundamentar su argumentación hace, por un lado, que el lector del artículo que posea un escaso conocimiento de las producciones etnográficas se vea obligado, a la hora de valorarlas, a acudir únicamente a su fe o falta de fe en la seriedad de los trabajos llevados 
sólo - por el hecho de no rescatarlas de la ignominia ateórica- que obras como Los Argonautas del Pacifico Occidental de Malinowski ${ }^{87}$, The Andaman Islanders de Radcliffe-Brown ${ }^{88}$, We, the Tikopia de Firth ${ }^{89}$, Magia, oráculos y brujería entre los azande de Evans-Pritchard ${ }^{90}$, The Tiv of Central Nigeria de Bohannan \& Bohannan ${ }^{91}$, Sistemas politicos de la Alta Birmania de Leach $^{92}$ o Divinidad y experiencia: la religión de los dinka de Lienhardt ${ }^{93}$ - para mentar exclusivamente monografías clásicas ligadas, por unas causas u otras, a la escuela británica de antropología socialno aspiran a generar teoría o no contienen generalizaciones de este tipo, significa o bien que no se conocen o, por el contrario, que se maneja un concepto de teoría que, de tan raro, se debería de explicitar aunque sólo fuera por cortesía o para facilitar la comprensión de lo que se argumenta ${ }^{94}$. A título ilustrativo, se puede sacar a colación que Ángel de Lucas ${ }^{95}$, en un interesante artículo donde refuta las hipótesis teóricas en que se apoya el liberalismo, ha acudido - entre otras- a la crítica que Malinowski

a cabo por representantes de las instituciones universitarias y, por otro lado, lleva a que aquel otro que tenga un mayor conocimiento de las mismas tenga que sobreesforzarse continuamente en imaginar en qué producciones etnográficas pueden estar pensando los autores cuando lanzan cada una de sus alegaciones.

87 Malinowski, B., Los Argonautas del Pacífico Occidental (Barcelona: Península, 1973 -1922-).

88 RADCLIFFE-BRown, A. R., The Andaman Islanders (Cambridge: Cambridge University Press, 1933 -1922-).

89 FirTH, R., We, The Tikopia (Londres: Allen \& Unwin, 1936).

90 EVANS-PRITCHARD, E., Magia, oráculos y brujería entre los azande (Barcelona: Anagrama, 1976 - 1937-).

91 Bohannan, L. y Bohannan, P., The Tiv of Central Nigeria (Londres: International African Institute, $1990-1936-)$.

92 LEACH, E., Sistemas políticos de la Alta Birmania (Barcelona: Anagrama, 1977 $-1954-)$.

93 LIENHARDT, Divinidad y experiencia: la religión de los dinka (Madrid: Akal, 1985 $-1961-)$.

94 Y no vale escudarse en que la investigación antropológica lo considera así: "La investigación antropológica considera que dicha fase de 'producción, recogida o captación de datos sobre el terreno' es la fuente imprescindible de la etnología (nivel de estudio comparativo) y la antropología propiamente dicha (nivel interpretativo, teórico, en otros términos, lugar de las generalizaciones sobre la naturaleza humana). Por tanto de la OP no se espera otra cosa que la recolección de material, la acumulación de descripciones y documentos" (p. 145).

95 DE LuCAS, A., "Sociedad de consumo o sociedad de mercado: el caso de las comunidades kula. Politica y Sociedad, n. ${ }^{\circ} 16$ (1994), pp. 25 y ss. 
realizó del concepto de bomo oeconomicus a partir de su etnografía de los trobriandeses.

Voy a finalizar aquí el comentario sobre las condiciones que Delgado y Gutiérrez atribuyen a la observación participante, no sin previamente expresar las razones por las que, a veces, cuando ellos han hablado de observación participante, yo he empleado los términos de trabajo de campo o de etnografía. En el mismo artículo que he mencionado antes ${ }^{96}$, me he hecho eco de la tremenda ambigüedad que entraña el uso a que son sometidas estas tres expresiones, lanzando al tiempo una propuesta fundamentada - eso creo- que busca poner un poco de orden en el caos terminológico existente ${ }^{97}$. Parto de la constatación de que las expresiones 'observación participante', 'trabajo de campo' y 'etnografía' son utilizadas muy a menudo de forma indistinta en el argot antropológico. Así, el vocablo 'observación participante' se emplea, al menos, con dos acepciones: por una parte, designa una técnica de observación stricto sensu consistente en la construcción de material empírico a través de lo que el antropólogo capta mediante sus sentidos (vista y oído, primordialmente), sin utilizar directamente otros instrumentos mediadores en sus relaciones con los sujetos o con la realidad ${ }^{98}$, así como participando en las actividades y en la vida cotidiana del grupo o de los grupos estudiados; pero, por otra parte, se llama también así al conjunto de técnicas y métodos de investigación (ya sea la observación documental, la entrevista en profundidad, el grupo de discusión, la confección de genealogías o redes sociales, la fotografía, etc.) que, junto con la propia observación directa, se instrumentalizan durante el trabajo de campo, pues no en vano la participación con los colectivos humanos da carácter y unas modulaciones especiales a esta clase de indagaciones. Cuando adquiere esta segunda acepción es, por tanto, cuando se origina la asimilación de la 'observación participante' con el 'trabajo de campo'. Voz esta última que, por lo común, admite igualmente dos significados: el expuesto hace un momento (combinación de conductas y de procedimientos de investigación a los que se recurre durante una fase concreta, la de pro-

\footnotetext{
96 Jociles, op. cit, pp. 110-111

97 Miguel S. VAlles ["Técnicas de observación y participación: de la observación participante a la investigación-acción-participativa", en Técnicas cualitativas de investigación social. Reflexión metodológica y práctica profesional (Madrid: Síntesis, 1997), pp. 144-145], desde el campo de la sociología, se ha ocupado asimismo de esta problemática terminológica y conceptual.

98 Con la expresión instrumentos mediadores no me refiero, por supuesto, a las categorías cognitivas con las que inevitablemente tiene que trabajar cualquier investigador, sino a los 'productos' que sitúa entre esas categorías y la realidad que pretende conocer, llámense cuestionario, test o cámara fotográfica.
} 
ducción de datos sobre el terreno), y otro mucho más amplio que viene a ser sinónimo de etnografía, entendida como todo el proceso que configura la investigación antropológica de carácter empírico, y que transcurre desde que surge el tema que se desea estudiar hasta que se tiene redactada la monografía, denominada también 'una etnografía'. De este modo, suelen establecerse equivalencias conceptuales entre los tres términos que adoptan una dirección ascendente, es decir, de abajo arriba (observación participante = trabajo de campo = etnografía), y no en una dirección descendente (de arriba abajo: etnografía $=$ trabajo de campo $=$ observación participante), lo que indudablemente lleva a un enriquecimiento y complejización conceptual de los que tienen más baja jerarquía metodológica. Pues bien, el empleo que de ellos hacen Delgado y Gutiérrez no coincide - ni tiene por qué coincidir, desde luego- con esta propuesta, pero tampoco con otras utilizaciones más o menos consensuadas en los ambientes antropológicos:

La etnografía no es la observación participante, sino su resultado. Pero en la medida en que observación participante y etnografía no pueden entenderse la una sin la otra, la reflexión crítica que propongo sobre la primera incluye también una reflexión sobre la segunda.. /La etnografía fue una técnica común ${ }^{99}$ a muchas disciplinas. En el caso concreto de la Europa del XIX, practican etnografía la medicina, las ciencias sociales, y los folcloristas... ${ }^{100}$.

Toda descripción etnográfica, para ser tenida por tal, debe estar basada en una investigación mediante observación participante o, para abreviar entre los antropólogos, por un trabajo de campo../..Podríamos incluso afirmar que la etnografía es lo que se hace y el resultado de investigar mediante $O P$, en sentido estricto, por lo cual no consideramos pertinente la expresión 'método etnográfico' que, en función de la disciplina desde la que se formule, suele recoger un cierto número siempre incompleto (y siempre entendido por un observador externo) de las cualidades de la OP antropológica ${ }^{101}$.

Parezca "pertinente" o no, el término antropológico de etnografía ha designado tanto el proceso de investigación (que, amén de la permanencia en el campo, exige - como se ha indicado- la observación y la participación en la vida cotidiana de los agentes sociales) como el resultado del mismo. Por tanto, restringir el vocablo a sólo este último no es más que otra señal de que la principal fuente de información de estos autores son los artículos de algunos postmodernos, cuyo 'proceso de investigación' ha consistido primordialmente en el examen de las retóricas

99 Si la etnografía no es la observación participante, sino su resultado, ¿qué tipo de técnica es?, ¿una técnica de escritura?

100 GuASCH, op. cit, pp. 12.

101 Delgado y GutiérReZ, op. cit., pp. 145. 
de las monografías realistas y/o experimentales y, por tanto, ése es el sentido que le han asignado en sus escritos.

\section{IV. ¿ES LA OBSERVACIÓN PARTICIPANTE INADECUADA PARA EL ESTUDIO DE LAS SOCIEDADES COMPLEJAS?}

A costa de parecer reiterativa (y poco avispada en las lides exegéticas), no tengo más remedio que volver a confesar la desazón que me embarga a la hora de encararme, esta vez, a uno de los primeros "problemas y limitaciones de la observación participante" formulados por Delgado y Gutiérrez: "la falta de operatividad de su noción de subjetividad colectiva cuando se intenta aplicar a fenómenos específicos de las modernas sociedades complejas pluriétnicas" ${ }^{102}$. La autoobservación de mis años de observadora participante no me proporciona claves para captar a qué puede apuntar aquella noción y, por consiguiente, menos aun para columbrar qué engendros subjeto-colectivos he podido construir que me han inhabilitado para investigar dichos fenómenos. $\mathrm{Ni}$ siquiera logro detectarlas en lo que conozco del trabajo de otros antropólogos o de obras teóricas sobre el tema. Es más, si abandono por unos instantes esta clase de indagaciones endogénicas $\mathrm{O}$, incluso, la búsqueda de "racionalidades subsidiarias" en el propio relato de Delgado y Gutiérrez, para no desechar "la categoría de lo imaginario, místico, mágico, etc." que pudiera hallarse en un sitio u otro ${ }^{103}$, me veo obligada a atestiguar mi falta de sensibilidad místicomágica cuando se trata de encontrar el significado de algo, de modo que, por ejemplo, la propia sonoridad del vocablo lo único que llega a evocarme es lo del 'inconsciente colectivo' de Jung o lo de las 'representaciones colectivas' de Durkheim: ies posible que aluda a alguna de estas cosas? Ahora bien, tal vez mi ceguera no tenga otra explicación que la enunciada desde el comienzo por Delgado y Gutiérrez: que habiéndome "desarrollado como especie humana bajo el mar, esta circunstancia será probablemente lo último" que descubra, es decir, que como el ya nombrado pez proverbial de Kluckhohn, estoy impedida no sólo de ver "las constricciones que impone a los análisis posibles la técnica del trabajo de campo y en concreto el rol de investigador participante" ${ }^{104}$, sino incluso de imaginar en qué puede consistir la "subjetividad colectiva". Por ello,

102 P. 148.

103 Como parecen aconsejar indirectamente a los investigadores (pp. 150), tal como se puede comprobar en un párrafo que reproduciremos más adelante.

104 P. 145. 
voy a acudir a lo que Delgado y Gutiérrez declaran justamente después de presentar la susodicha "implicación" o "problema", por si acaso constituye un intento de clarificar lo que desean decir:

Entre las objeciones que tiene planteada la metodología de la OP destaca la falta de operatividad de su noción de 'subjetividad colectiva' cuando se intenta aplicar a fenómenos específicos de las modernas sociedades complejas pluriétnicas. Así por ejemplo supone forzar el viejo concepto antropológico referirse a 'la cultura del alcohol' entre los jóvenes madrileños, la 'cultura del pelotazo' para referirse a la 'tribu' de los brokers, etc./ La idea de 'subjetividad cultural' (colectiva, previa a la emergencia de sujetos) está vinculada genealógicamente con las nociones de genotipo, pueblo primitivo o inconsciente./ Primeramente, existe una unidad de la mente humana, una especie de estructura genotípica común que se comprueba no tanto en la adquisición de una cultura concreta, sino por la incorporación necesaria de todo sujeto a una 'subjetividad cultural' con unas estructuras esenciales comunes./ En segundo lugar, una de sus condiciones pragmáticas es la existencia de un sistema que se considera a sí mismo organizacionalmente cerrado: modelo proporcionado por la antropología cultural de los llamados pueblos primitivos o, en su defecto, de las comunidades. En una ciudad occidental la desigualdad en la distribución del conocimiento es mucho mayor que en una aldea bororo, las fronteras del sistema son más permeables, las identidades simbólicas en que se expresa el contenido de aquella subjetividad son múltiples y no están sincronizadas, emerge el mundo de los sistemas autoorganizados, sus acoplamientos, frotamientos, etc. Por decirlo de otro modo, una determinada cultura, en el significado clásico del término para la antropología cultural (y en el aquí expuesto como producto de la observación participante) no está constituyendo ya el único 'modelo cognitivo y operativo' (en términos de Rapapport) de una comunidad pequeña y relativamente independiente./ En tercer lugar, se ha considerado tradicionalmente que dicha 'subjetividad colectiva' no es consciente, no es describible por sus actores, y que sus significados sólo pueden ser esclarecidos desde un punto de vista exterior o más 'objetivo'. Se identifica el interior de un sistema dado como incapaz de dar cuenta de sí mismo, y el exterior del mismo como ámbito de la única forma de reflexividad o conciencia posibles. La perspectiva del analista se considera la depositaria de las 'estructuras esenciales', capaces de desvelar los casos particulares de la perspectiva de los actores de una determinada cultura (Bueno, 1990: 85) ${ }^{105}$.

El principio de "la unidad de la mente humana" ha gozado de significados y pretensiones variopintas en el transcurso de la historia de la disciplina. Ya utilizado desde mediados del XIX, para los evolucionistas decimonónicos, entrañaba la convicción — puesta de manifiesto, v.g., por Harris ${ }^{106}$ - de que el hombre de cualquier época y lugar es capaz de las

\footnotetext{
105 P. 149.

106 HARRIS, M., El desarrollo de la teoría antropológica (Madrid: Siglo XXI, 1987 -1968-), pp. 151 y ss.
} 
mismas invenciones, si se encuentra ante necesidades y condiciones similares, mientras que para Lévi-Strauss y el estructuralismo, en cambio, ese principio se concreta en conjeturar la existencia de estructuras subyacentes de la mente humana o, como para Sperber, de propiedades universales del entendimiento, tal como recuerda Enrique Luque ${ }^{107}$, quien plantea el interrogante de si estas concepciones estructuralistas no suponen la vuelta "al viejo problema - hoy tan cuestionado- del sustrato universal y homogéneo de la diversidad cultural. Añade Luque que tales planteamientos (los de Lévi-Strauss) son afines a los de la lingüística estructural de Chomsky, a pesar de las discrepancias que se puedan apreciar entre ellos, pues "éstas parecen afectar más a los resultados de la aplicación de un método [se refiere al llamado método estructuralista, no a la observación participante] que a algunos supuestos teóricos en los que, sin duda, concuerdan el lingüista y el antropólogo" ${ }^{108}$. Yendo al grano: dado que el estructuralismo contempla aquellas estructuras o propiedades como universales y, además, como inconscientes, es posible que Delgado y Gutiérrez estén pensando en ellas cuando hablan de "subjetividad colectiva" o "subjetividad culturalw. Ahora bien, en tal supuesto, es preciso resaltar -en primer lugar- que aquellos constructos teóricos no son "problemas" o "implicaciones" de la observación participante, sino fruto de predicar la existencia en el cerebro o en la mente (pues Lévi-Strauss no los diferencia) de unas estructuras que el método estructuralista se encarga de desvelar a partir de material empírico de diferente naturaleza y origen, eso sí, guiado por un teoría que tiene como a priori el arraigo de tales estructuras en la biología y/o en la psique humana, cerrándose así el círculo explicativo. Y, en segundo lugar, que el manejo que Delgado y Gutiérrez hacen de la expresión "subjetividad cultural" es inadecuado, al menos en lo que se refiere al adjetivo que la califica ${ }^{109}$; ante todo, porque las estructuras subyacentes lévi-straussianas son consideradas — como afirmaba Luque más arriba - ael sustrato universal y homogéneo de la diversidad cultural", pero un sustrato que, siendo condición de posibilidad de la cultura, no es equiparable a ella: las estructuras mentales son estrictamente formales $\mathrm{y}$, sin los contenidos procedentes de las circunstancias mate-

\footnotetext{
107 LuQue, E., Del conocimiento antropológico (Madrid: Siglo XXI-CIS, 1984), pp. 153 y ss.

108 LuQue, op. cit., pp. 154-155.

109 En cuanto al de subjetividad, o es un término con el que simplemente se quiere nombrar aquellas estructuras subyacentes de la psique (o las representaciones colectivas de las que luego hablaremos) o, si no, cuesta hacerse una idea sobre qué pudiera ser una subjetividad sin sujetos.
} 
riales específicas de la vida de cada sociedad, permanecerían vacías, no podrían ser tenidas por culturales. Con todo, es preciso reconocer que la hipótesis de la existencia de estructuras mentales universales es lo que, desde la óptica del estructuralismo, asienta la posibilidad de la traducción y la comparación intercultural y, por tanto, de conocer otras culturas (si bien no sólo a través de la observación participante o de experiencias directas de registro $\left.{ }^{110}\right)$, tal como Delgado y Gutiérrez aseveran en otro lugar, pero con relación a la antropología en general:

El hecho de hacer antropología es construido mediante la comparación de distintos grupos observados desde un mismo punto de vista común (la comunidad de antropólogos) y empleando siempre una estrategia de observación 'participante' asentada en la premisa de que existe un código o combinatoria cultural de carácter universal (la naturaleza humana) ${ }^{111}$ que puede descodificarse mediante una experiencia directa de registro de la cultura extraña, y un análisis posterior de su infraestructura simbólica o su trama de significados latentes ${ }^{112}$.

Sin embargo, hay antropólogos que o bien niegan la posibilidad misma de la comparación intercultural (y, desde luego, también la existencia de universales culturales: precisamente los que apoyan la tesis epistemológica del relativismo) o bien, defendiéndola, no creen que "la comunidad de antropólogos" participe de "un mismo punto de vista", por lo que recelan de que sea viable tal comparación a no ser que se haya partido de proyectos que han lanzado 'las mismas redes' a la realidad, o bien -apoyándola igualmente- no subscriben la teoría lévi-straussiana sobre las estructuras subyacentes de la mente humana, sino que ubican, por ejemplo, los universales en necesidades biológicas, psicológicas o sociológicas de la humanidad y/o en contenidos culturales mínimos compartidos por toda ella, que en ningún caso son mostrados - al menos expresamentecomo inconscientes, tal como sucede con los teóricos del consensus gentium que Clifford Geertz ataca profusamente en La interpretación de las culturas ${ }^{113}$ y particulariza en las figuras de Wissler, Malinowski, Murdock

110 La prueba se encuentra en el propio Lévi-Strauss, que ha sometido a traducción y comparación intercultural no sólo el material registrado directamente por él (entre los bororo, nambikuara o caduveu, v.g.), sino casi todo el que cayó en sus manos sobre los temas de parentesco o de mitología, por ejemplo, ya hubiera sido registrado por antropólogos, sociólogos, historiadores, literatos, juristas, viajeros o, para terminar, misioneros.

111 Y cabe preguntarse: ¿es acaso lo mismo la "naturaleza", por muy humana que sea, que la "combinatoria cultural", por muy universal que resulte?

112 P. 145.

113 Geertz, C., La interpretación de las culturas (Barcelona: Gedisa, 1987 -1973-), pp. 46 y ss. 
y Kluckhohn. Dejando de lado los problemas de la comparación y la traducción interculturales, bien pudiera ser que Delgado y Gutiérrez estén relacionando implícitamente su concepto de "subjetividad cultural" no ya con éstas o con las precedentes nociones de cultura, sino con la de representaciones colectivas indicada más arriba, y que — según Bourdieu ${ }^{114}$, v.g.- - beneficia una concepción "de la producción cultural como colectiva, impersonal, en suma, sin productores". Pero en ese caso, aun cuando se admita —-como es de rigor - la influencia de la sociología durkheimiana no sólo sobre sociólogos posteriores, sino también sobre buen número de antropólogos que han hecho uso de la observación participante, no hay que pasar por alto que el creador de la misma, Durkheim, —que yo sepa- nunca la practicó, como tampoco muchos de sus seguidores (incluido Marcel Mauss).

$\mathrm{Y}$ con todo lo precedente, bastante poco he avanzado si lo que procuraba era sólo descubrir cuál es la idea de "subjetividad cultural" o "subjetividad colectiva" que, siendo "implicación" de la observación participante, le resta operatividad cuando es aplicada a estudiar "fenómenos específicos de las modernas sociedades complejas pluriétnicas". No obstante, no creo haber perdido el tiempo, puesto que el repaso de diferentes conceptos antropológicos y sociológicos a los que, por mor de cierto aire de familia, pudiera estar conectado el de "subjetividad cultural", me ha permitido poner de relieve varios aspectos - para mí- importantes: en primer lugar, que si se aspira a hablar con propiedad, no es de recibo dar por sentado el empleo de una sola concepción antropológica de cultura, sino de múltiples concepciones; en segundo lugar, que no hay rasgos comunes a todas ellas que legitime deducir que la antropología o el observador participante, sin más, trabaja con (o produce) constructos teóricos que, al hipostasiar unas estructuras o representaciones inconscientes y colectivas, se olvida de los sujetos sociales ${ }^{115}$; en tercer lugar, que tales constructos -llámeseles "subjetividades culturales" o como se prefiera-,

114 Bourdieu, P., El sentido práctico, edición citada, p. 39.

115 Lo que no quiere decir, por supuesto, que no haya rasgos comunes, algunos de los cuales han sido descritos hace poco por Antonio AriÑo [Sociología de la cultura. La constitución simbólica de la sociedad (Barcelona: Ariel, 1997), pp. 45-46], aunque dudo que los que señala con los números 2 ("La cultura consiste en un sistema de símbolos..."), 4 ("La cultura es colectiva y pública. Se expresa en formas institucionalizadas y es objetiva.."), 7 ("La cultura es práctica. Es antes una actividad que una forma de conocimiento.."), 10 ("El corolario de la característica anterior [su relatividad] es la dignidad equivalente de todas las culturas...) y 12 ("La relación entre cultura y sociedad tiende a ser interpretada como armónica...") sean extrapolables a todas las concepciones empleadas por los antropólogos. 
quizá por ser teóricos, no están inevitablemente asociados a la observación participante, sino que - por el contrario- han sido patrimonio de científicos sociales que no se han acercado a ella ni por afición, así como rechazados por otros que la han convertido, incluso, en el emblema de su disciplina; y, por último, que de ser esto así, difícilmente puede aceptarse la cábala de que la observación participante sea poco operativa para el estudio de las sociedades complejas a fuer de cargar con la idea de "Subjetividad cultural" como lastre ineludible.

Cabría pensar que, para argumentar contra planteamientos como éstos, podría ahorrarme esfuerzo, traslados por la historia de la antropología y elucubraciones engorrosas poniéndome sencillamente a enumerar y describir las investigaciones etnográficas que - a pesar de pretendidas dificultades como concebir la cultura como "subjetividad colectiva" - se han dirigido a dilucidar "fenómenos específicos de las modernas sociedades complejas pluriétnicas"; arrancando - por hacerlo desde algún sitiode las realizadas por la escuela de Manchester en ciudades europeas, africanas y asiáticas desde la segunda mitad de la década de los cincuenta, y terminando por las tesis doctorales presentadas recientemente en departamentos de antropología españoles, como la de Rafael Cuesta sobre la factoría Suzuki de Linares. Pero estoy convencida de que quienes se consideran en posesión de los ungüentos mágicos, o de los remedios sintéticos de última generación, capaces de acabar con los males disciplinares o científico-sociales, enseguida se las ingeniarían para encontrar en ellas primitivizaciones, subculturas marginales, obliteración de los sujetos, extranjerización, mimetizaciones de los modelos hegemónicos, subjetividades colectivas o - para no eternizar la retahíla - síntomas de realismo etnográfico; por lo que no me libraría de tener que volver a los mismos esfuerzos, traslados y elucubraciones que hubiera deseado evitarme. Por tanto, me dispongo a continuar con el análisis teórico-conceptual del posicionamiento de Delgado y Gutiérrez; en particular, con el de "una de las condiciones pragmáticas" en que descansa —en su opinión- la idea de "subjetividad cultural".

Se trata — según dicen- de "la existencia de un sistema que se considera a sí mismo organizacionalmente cerrado: modelo proporcionado por la antropología cultural de los llamados pueblos primitivos o, en su defecto, de las comunidades", es decir, de una cuestión de la que ya tuve ocasión de ocuparme en el anterior apartado de este artículo. Así, aquí voy a limitarme a abordarla desde otros puntos de vista: primero, que no vislumbro fácilmente su ligazón con la noción de "subjetividad colectiva", a no ser que ésta no entrañe otra cosa que el no-reconocimiento de la diversidad cultural en el interior de los sistemas estudiados, como pudie- 
ra insinuar la frase que sigue en el texto de Delgado y Gutiérrez (pero, en esa tesitura, se estarían mezclando asuntos de distinta naturaleza teórica y metodológica) y, segundo, que toda esta amalgama de escollos teóricos, metodológicos y/o epistemológicos han sido enfrentados por los etnógrafos desde hace ya algunas décadas y, en algunos casos, consiguiendo superarlos en sus investigaciones empíricas desde diferentes propuestas; o, dicho de otra forma: ni la antropología — como he insistido- ha sido alguna vez un bloque unitario de concepciones sobre la cultura, presupuestos epistemológicos o enfoques metodológicos, ni la observación participante o la propia antropología social son hoy en día lo que eran hace 40 ó 70 años, entre otros motivos, porque los antropólogos se han ido ocupando de cribar, en la etnografía clásica (y no sólo en ella), lo que han estimado válido de aquello otro que no lo era tanto para encarar nuevas situaciones y, aun - icómo no!-, las antiguas. Es más, todo este proceso —-todavía no acabado, afortunadamente- no se ha llevado a cabo dentro de una jaula de cristal, sino teniendo en cuenta las aportaciones de etnógrafos vinculados a otras disciplinas (primordialmente la sociología y la psicología social), las críticas coherentes y contrastadas que se han efectuado desde ellas o, para mencionar solamente una cosa más, los marcos teórico-metodológicos debidos a pensadores como Gadamer, Ricoeur, Berger, Luckman, Giddens o Bourdieu ${ }^{116}$ que, en lo que se refiere a la etnografía española, han inseminado tempranamente ${ }^{117}$ estudios concretos de carácter empírico (sirvan como botón de muestra el efectuado por Dolors Comas ${ }^{118}$ sobre las estrategias hereditarias en el Pirineo aragonés o el de Marie Jose Devillard ${ }^{119}$ sobre grupos domésticos salmantinos).

116 Una anécdota personal: siendo estudiante en la Facultad de Sociología durante los años de la transición política, cuando algunos profesores 'progres' de la misma me hacían aprender el Marta Harnecker como si fuera un catecismo y conocer al dedillo casi toda la producción bibliográfica de Althusser, los únicos que me introdujeron, por ejemplo, en el pensamiento de Bourdieu fueron un sociólogo, Jesús Ibáñez (a través de El oficio de sociólogo), y dos antropólogos, Ricardo Sanmartín y Marie Jose Devillard (mediante Esquisse d'une théorie de la practique, précédé de trois études d'ethnologie kabyle y "Les stratégies matrimoniales dans le système des stratégies de reproduction").

117 Téngase en consideración que la antropología española no se institucionaliza hasta bien entrados los años setenta.

118 COMAS, D., "Sistema de herencia y estratificación social: las estrategias hereditarias", en PujadAs, J. J. y COMAs, D., Estudios de antropología social en el Pirineo aragonés (Zaragoza: Diputación General de Aragón, 1994 -1980-).

119 Devillard, M. J., De lo mio a lo de nadie. Individualismo, colectivismo agrario y vida cotidiana (Madrid: CIS, 1993). 
El tema de la apertura de los sistemas sociales —que dejé a medio comentar hace un momento- contiene, por lo menos, dos cuestiones diferentes: por un lado, la imagen que dichos sistemas tengan de sí mismos a este respecto; $y$, por otro, la que tenga el investigador, en función de factores de muy diversa índole cuya especificación no tiene sentido hacer aquí. Pues bien, desde mi perspectiva, que el sistema estudiado por los observadores participantes se considere a sí mismo organizacionalmente cerrado - tal como Delgado y Gutiérrez afirman que ocurre- no es en absoluto un impedimento que pueda afectar a la aplicabilidad de una técnica o metodología de investigación a un determinado campo social (ni es posible que genere ninguna noción antropológica, como la pretendida de "subjetividad cultural"), a no ser, por supuesto, que tal consideración fuera contagiada al investigador. $\mathrm{O}$, dicho con otras palabras, estimo - de entrada - que no hay ni ha habido ningún sistema social que, sin caer en error de apreciación, pueda ser tenido por los investigadores como cerrado, aislado o sin relaciones dialécticas con su entorno social, político, cultural o medioambiental. Es cierto - no cabe duda- que los científicos sociales han establecido tipos y escalas de apertura entre las diferentes sociedades, pero tales escalas lo único que alcanzan a señalar es la mayor o menor intensidad, frecuencia o necesidad, por ejemplo, de tales interrelaciones, ya que se presentan como escalas ordinales que en ningún caso pueden encontrar empíricamente un punto cero, esto es, una clase de sociedad que no tenga algún grado de apertura. Es más, las críticas más agudas y certeras que, desde los años sesenta, se lanzaron a los estudios clásicos sobre "pueblos primitivos o, en su defecto, comunidades", no estaban dirigidas a cuestionar que se investigaran sistemas cerrados, sino a que se hiciera como si lo fueran, es decir, sin tener en cuenta que tales pueblos o comunidades, al igual que "una ciudad occidental", formaban parte de una sociedad más compleja. Estoy enteramente de acuerdo con Joan Frigolé ${ }^{120}$ cuando mantiene, si bien ubicando la discusión en otro plano, que afirmar que existen unos conceptos o modelos que no son válidos para las localidades grandes, no implica que estos modelos lo sean para las pequeñas". Nos topamos, por consiguiente, con un problema de carácter teórico-metodológico (no referente a la naturaleza de las sociedades estudiadas), que -efectivamente- ha viciado bastantes investigaciones etnográficas pero de comunidades y pueblos primitivos tanto como de sociedades complejas. Un problema que algunos antropólogos 'excéntricos' trajeron consigo cuando se decidieron, desde mediados de los 50, a trasladar sus pesquisas a la península ibérica, y

120 FRIGOLÉ, J., “Replantear problemas y modelos”. Antropología, n. 3 (1992), p. 82. 
que, además, no ha desaparecido totalmente en nuestros días a pesar de los múltiples ensayos críticos que se le han dedicado.

Por otra parte, si es verdad (como ocurre a veces) que los observadores participantes se dejan llevar por la idea que un sistema tiene de sí mismo - en este caso- como "organizacionalmente cerrado", ello sería así como consecuencia de primar la perspectiva emic sobre la etic ${ }^{121} \mathrm{o}$, dicho en otros términos, de pensar - al contrario de lo que afirman Delgado y Gutiérrez algo más adelante- que ael interior de un sistema dado es capaz de dar cuenta de sín y que, por consiguiente, "el exterior del mismo no es la única forma de reflexividad o conciencia posibles". Ahora bien, dejando de lado la búsqueda de presumibles incongruencias en el texto que examinamos y retornando al asunto que nos ocupaba, es preciso decir que ese 'contagio ideacional' del que hablaba hace un momento puede constituir una de las razones por las cuales resulta tan difícil desterrar de la etnografía una concepción como aquélla sobre las fronteras de los sistemas que se estudian, pues no sólo los pueblos primitivos o las comunidades rurales la tienen, sino también los institutos de bachillerato, las facultades universitarias, las empresas...y un largo etcétera de entidades urbanas: para darse cuenta no hace falta más que pertenecer a ellas y/o investigarlas durante largo tiempo. Sin embargo, no es 'el contagio ideacional' la única razón posible: Enrique Luque ${ }^{122}$, por ejemplo, atribuye "la incomprensión de no pocos fenómenos de fluidez y de permeabilidad de los límites" a la tendencia de los antropólogos a "exagerar diversidades y discontinuidades" culturales. Y es Marie Jose Devillard, entre otros, quien relaciona el problema que estamos tratando con la observación participante, pero de una forma notablemente diferente a como lo hacen Delgado y Gutiérrez. Primero, porque no busca asentar en él la emergencia de una supuesta noción antropológica de "subjetividad culturaln; segundo, porque no lo concibe como algo irresoluble cuando se recurre a la observación participante $\mathrm{y}$, tercero, porque lo ubica en las especiales circunstancias en que se desarrolla el trabajo de campo etnográfico:

[Hablando de su trabajo en Salamanca] (E)ra preciso introducir en el análisis una doble dimensión externa, espacial y temporal a la vez, a las que el trabajo de campo no predispone de buenas a primeras. La posición del investigador respecto $a$ y en la comunidad, la preferencia por el análisis prolongado e intensivo, y la inmersión en los problemas y situaciones locales a las que está obligado difi-

121 Como posibilidad también cabe que se prime la perspectiva emic porque coincida con la etic.

122 LuQue, E., Antropología política. Ensayos críticos (Barcelona: Ariel, 1996), p. 88. 
cultan y no le inclinan a perfilar con exactitud la complejidad y naturaleza real de los hechos estudiados. En este sentido, tanto el marco histórico como el encaje de las comunidades estudiadas en la región... responden menos al objetivo de situarlas que al de proporcionar unas dimensiones espaciales y temporales que consideré en todo momento como hechos presentes, en cierto modo, en aquello mismo que observaba sincrónica y localmente ${ }^{123}$.

Haré un alto en el camino para aclarar mi postura: no pongo en duda (¡sería una insensatez!) que ciertas condiciones en que se lleva a cabo el trabajo de campo, como las señaladas por Devillard — por ejemplo-, puedan tener incidencias en los resultados de la investigación etnográfica ni que, con frecuencia, la tengan; lo que no comparto es que se conciba como algo que está fuera de toda posibilidad de control por parte del observador participante (de ahí mi insistencia en la vigilancia epistemológica $y$, dentro de ella, en la 'distancia analítica') o que quienes aquello sostienen no se tomen la molestia de explicitar cómo se produce el proceso. Es decir, lo que no es aceptable es que se formulen algunas aseveraciones deshilvanadas sobre las supuestas subjetividades culturales, los sistemas que se consideran organizacionalmente cerrados, el no-reconocimiento de la heterogeneidad intracultural o el objetivismo etnográfico, así como que se diga taxativamente que todo esto está vinculado con la observación participante, sin que se haga el menor amago de mostrar cómo se interrelacionan teóricamente unas cosas con otras. Delgado y Gutiérrez parecen creer que las tan repetidas subjetividades culturales son fruto de la observación participante, pero ¿cómo las genera ésta?, ¿y cómo se relaciona todo lo demás con cualquiera de las dos? ¿Son los sistemas autoconsiderados organizacionalmente cerrados lo mismo que el no-reconocimiento de la heterogeneidad intracultural, dado que un ejemplo de esto último es ofrecido, o eso se da a entender, como ilustración de aquello otro? ¿Es el objetivismo algo intrínseco a la observación participante o depende de los marcos teóricos de los que parten sus practicantes? ¿Cuáles son las circunstancias en que la OP lleva a obviar la heterogeneidad intracultural, o lo hace de forma ineludible? Las respuestas a preguntas como éstas, imprescindibles para articular tesis como las abogadas por Delgado y Gutiérrez, son abandonadas al buen criterio (o al buen tuntún) del lector que esté mínimamente interesado por el tema. Y como -al menos- yo no he dejado de estarlo, voy a intentar encontrar una contestación, por lo menos, a la última que he planteado.

"En una ciudad occidental la desigualdad en la distribución del conocimiento es mucho mayor que en una aldea bororo", dicen Delgado y

123 DEVILlaRD, op. cit., pp. 276-277. 
Gutiérrez —en una frase que rescato de la cita que inserté al principio de este tercer apartado - añadiendo: "una determinada cultura, en el significado clásico del término para la antropología cultural (y en el aquí expuesto como producto de la observación participante) no está constituyendo ya el único modelo cognitivo y operativo... de una comunidad pequeña y relativamente independienten. Es decir, que - parafraseando a Frigolé- nos volvemos a encontrar con la misma clase de paralogismos: entender que porque la imagen de homogeneidad intracultural no es válida para "la ciudad occidental", sí lo es, en cambio, para "las sociedades primitivas" o "las comunidades". Pero, realmente ihan negado los antropólogos la heterogeneidad de estas últimas? Tal como lo plantea, v.g., Antonio Ariño ${ }^{124}$, tras analizar la posición a este respecto de Ruth Benedict, lo que sucede es que se da un mayor "énfasis en la cultura común del grupo y en su carácter coherente e integrador", pero un énfasis que "no implica desconocimiento de la diversidad interna (derivada del ciclo de edades, de las actividades o del ambiente)n. Es más, recurre a dos explicaciones ("una de tipo metodológico y la otra de carácter teórico") que permiten apreciar un intento de no dejar cojas sus opiniones: primero, el centramiento del etnógrafo en el estudio de pequeñas. comunidades, donde un individuo podría dominar todos sus contenidos ${ }^{125} \mathrm{y}$, segundo, la identificación de la cultura con los valores del grupo social inculcados a sus miembros, que ha operado con el supuesto de que la cultura, como el lenguaje, debe ser compartida. Para mí, este segundo tipo de justificación es bastante más convincente que el primero, en el sentido de que presumo que la proyección de una imagen de la sociedad como un ente coherente y homogéneo depende más del concepto que el investigador tenga de comunidad (o de cultura), así como de determinadas formas de practicar el trabajo de campo, que del hecho de que se estudie en pequeñas o grandes comunidades. Un ejemplo lo proporciona el mismo Ariño al hacer notar la aparente paradoja de que uel exponente más sistemático de la teoría de la cultura común en las ciencias sociales modernas... [sea] un sociólogo, Talcott Parsons, quien partiendo del problema del orden ly no precisamente en las comunidades pequeñas], intenta explicar la estabilidad social en términos de la íntima interdependencia de los patrones culturales, la institucionalización y las necesidades personales" ${ }^{126}$. No obs-

\footnotetext{
124 ARIÑO, op. cit., p. 30.

125 Esto sería así sólo si la cultura de una pequeña comunidad fuera realmente homogénea y tuviera límites precisos.

126 ARIÑO, op. cit., pp. 30-31.
} 
tante, descubro la mejor ilustración de lo que quiero expresar en un artículo de José Luis García titulado "QQué tienen que ver los españoles con lo que los antropólogos saben de ellos?.. Aquí, el autor expone el modo en que, mediante el análisis de las clasificaciones que algunos de sus informantes de diferentes edades realizaron de los vegetales comestibles, pudo llegar a la constatación, en primer lugar, de que - al contrario de lo que pensaban, v.g., los etnocientíficos- "se da una diversidad de formas coexistentes de organización cognitiva dentro de una misma comunidad"; y, en segundo lugar, de que "es posible verificar criterios, más que sistemas de clasificación"; por lo que continúa declarando: "Mis informantes reiteran criterios particulares en globalidades distintas. Así, por ejemplo, tres informantes utilizan como criterio de clasificación 'frutos que se utilizan para hacer el caldo', pero lo hacen dentro de sistemas distintos" ${ }^{127}$. Lo que quiero destacar de este trabajo es, sobre todo, que la investigación a la que se refiere José Luís García es etnográfica y, después, que fue llevada a cabo en pequeñas comunidades rurales del occidente asturiano, y ¿acaso tenemos que prejuzgar que son más heterogéneas que los pueblos primitivos estudiados por los etnógrafos clásicos? La presencia de diferentes sistemas culturales dentro de una misma sociedad (e incluso dentro de un mismo individuo), al igual que la existencia de fronteras permeables, no es algo que afecte tan sólo a "una ciudad occidental" o a los ilongot filipinos que sufren un fuerte proceso de aculturación (caso que tomo de la etnografía de Rosaldo), sino también a una aldea bororo o a una comunidad rural. Pero, para cambiar de tercio, voy a reproducir seguidamente unas palabras de García que encierran un posible motivo por el cual se ha subrayado poco la heterogeneidad intracultural:

(E)n vez de valorar el discurso nativo como conducta que observamos y debemos interpretar, lo tomamos como interpretación en sí de los acontecimientos. De esta manera la investigación de los fenómenos culturales se presenta en la antropología profundamente mediada por la visión del nativo. Es una simpleza pensar que ésta sólo incide en aquellos temas antropológicos que tienen que ver con las estructuras cognitivas o ideológicas del nativo.. El nativo cuando habla de su propia cultura hace exactamente lo mismo [que el investigador en su vida cotidianal: generaliza, argumenta, selecciona, combina, crea, en definitiva, una cierta realidad por medio de su discurso. Cuando los antropólogos tomamos como discurso referencial válido la información del nativo, y no la analizamos como conducta, estamos siendo 'cómplices' de esa deformación de la realidad. El problema está en que el nativo, aunque construya homogéneamente esa realidad, conoce

127 García, J.L., "¿Qué tienen que ver los españoles con lo que los antropólogos saben de ellos?», en CÁTEDRA, M. (ed), Los españoles vistos por los antropólogos (Gijón: Júcar, 1991), pp. 117. 
perfectamente las diferencias internas que no resalta, mientras que el antropólogo las ignora ${ }^{128}$.

Es decir, según García, la tendencia de los etnógrafos a marcar lo que es general, lo que es compartido, la cultura como algo homogéneo... puede encontrar sus raíces en el hecho de que aquéllos, habida cuenta que privilegian la información sobre la observación directa, dan prioridad a la perspectiva de los agentes sociales, a la capacidad de un sistema para - usando de nuevo las palabras de Delgado y Gutiérrez- "dar cuenta de sí mismo", a la consideración de que la cultura "es describible por sus actores" o, dicho en otros términos, a unos factores que, desde la óptica de estos dos últimos autores, son relegados por los observadores participantes por una supuesta visión del exterior del sistema que estudian "como la única forma de reflexividad o conciencia posibles". En suma, que mientras García enfatiza la inclinación de la etnografía al subjetivismo, Delgado y Gutiérrez la acusan de objetivismo. ¿Con qué postura quedarse? Pues, así trazadas, con ninguna de ellas, si bien he de confesar mi mayor proximidad a la de José Luís García, que - por otro lado- es bastante más elaborada de lo que deja ver el texto que he presentado. Estando de acuerdo con él en que los etnógrafos basan sus informes a menudo más en la 'información' que recaban de los agentes sociales que en la propia 'observación' ${ }^{129}$, sospecho - empero- que esta causa por sí sola no da cuenta de la propensión de ciertas monografías a destacar la cultura común, al menos no sin la intervención de otras consideraciones, como la excesiva habitualidad con que algunos se dejan seducir por uno o unos

\footnotetext{
128 GarCía, op. cit., pp. 114-115.

129 En otra obra, donde hace un examen de la evolución que ha sufrido el tratamiento del discurso de los informantes dentro de la antropología, García [ "El análisis del discurso en la antropología social", en GarCía, J. L. (coord.), Etnolingüística y análisis del discurso (Zaragoza: VII Congreso de Antropología Social, 1996), pp. 11-17], nos habla de la principal razón por la cual, a veces, los etnógrafos se orientan a enfocar ese discurso como "descripciones objetivas de la realidad", esto es, como 'información' y no como 'conducta': cuando la realidad que se quiere investigar "no ha sido directamente observada, bien porque el período de trabajo de campo es corto, bien porque se trata de comportamientos menos públicos o simplemente porque son hechos de un pasado próximo o lejano". En otro orden de cosas, cabe decir que resulta difícil determinar si el hecho de que los etnógrafos hagan, en sus monografías, un mayor uso de la información que de la observación se debe realmente a que hayan priorizado el primer tipo de datos sobre el segundo en sus investigaciones o, por el contrario, a un matiz de estilo literario; dicho de otro modo, puede ocurrir -como me indica Ricardo Sanmartín- que la información, al ser "citable", se utilice en las monografías para dar la impresión de mayor rigor, por cuanto parece ser «una prueba que prueba más" que las observaciones del etnógrafo.
} 
pocos 'informantes bien informados', puesto que en las ocasiones en que se diversifican estratégicamente las fuentes y las discrepancias entre ellas se acogen como un aspecto a explicar (y no como algo a ocultar), la heterogeneidad cultural se refleja indeleblemente en los resultados de la investigación.

Y entro de lleno, ipor fin!, en uno de los temas más peliagudos y que, a pesar de los conatos que he tenido varias veces de meterme en él, he preferido dejar para el final: el del estatuto epistemológico que se le concede a la perspectiva de los agentes sociales en la etnografía, tanto en su carácter de proceso de investigación como en su vertiente de monografía acabada. Un asunto que Delgado y Gutiérrez, aparte de concebir como una de las condiciones (¿o es una de las implicaciones?) de la noción de subjetividad cultural, presentan también como el segundo gran "problema o limitación" de la observación participante:

"Ahora bien, junto a estos problemas de 'aplicabilidad' contemporánea de determinadas premisas de la $O \mathrm{OP}^{130}$, existen críticas a las nociones de sujeto y mente que están implicadas en sus condiciones y epistemología, a partir de las cuales la OP muestra sus limitaciones incluso en referencia a conceptos sociológicos complejos como el de sistema social autoorganizado o el de Individuo ${ }^{131} \ldots /$ En primer lugar, la OP lleva a cabo una reducción de la complejidad del sujeto a la hora de comprender las acciones de los sujetos: la reflexividad, los valores personales, la conciencia, el deseo son obstáculos para el conocimiento de la realidad global de un objeto de investigación. Así ocurre que la OP produce el efecto de que no existen demasiadas diferencias entre los sujetos de una misma tribu ${ }^{132}$, la unidad de la misma se convierte en el tipo ideal del que se está informando, y las especificidades de los sujetos son desechables...[] Reducir el nivel de subjetividad y reflexividad del objeto (grupo humano estudiado) por debajo del nivel de subjetividad y reflexividad del sujeto investigador implica una decisión metodológica positivista: prescindir de unas así llamadas 'propiedades secundarias' de los objetos que hace posible un conocimiento científico.../En segundo lugar, desde la universalización de la idea de relativismo cultural.., concediendo al objeto de investigación la misma capacidad de subjetividad y objetividad que la que se presupone en el sujeto investigador, se espera del 'nativo' un comportamiento racional isomorfo de la concepción de la racionalidad del analista, desechando las diver-

130 ¿No era de la OP sin más?

131 Da la impresión de que se estipula aquí la existencia de unas barreras disciplinares entre sociología y antropología diseñadas alrededor de la disyuntiva 'complejo'/'simple', que concernerían no sólo al tipo de sociedades estudiadas sino a la sofisticación de los conceptos empleados en cada una de ellas.

132 ¿Cómo consecuencia de lo que se afirma inmediatamente antes?: ¿el considerar la reflexividad de los sujetos como obstáculo para el conocimiento es lo que lleva (o se identifica con) el no-reconocimiento de "las diferencias entre los sujetos de la misma tribu?? 
gencias hacia la categoría de lo imaginario, místico, mágico, etc. Este es el esfuerzo típicamente desarrollado por la antropología cultural: encargarse de encontrar las racionalidades subsidiarias e inconscientes de diferentes grupos humanos que tienen expresión en el dominio simbólico...[] Lo que importa destacar en términos de limitaciones de la OP es la implicación efectiva de esta teoría de la mente y las consiguientes dificultades para investigar la complejidad de las modernas sociedades industriales ${ }^{133}$.

Estimo, de partida, que la observación participante (amén de la entrevista semiestructurada o los grupos de discusión, por ejemplo) ofrece más oportunidades al investigador de tener en cuenta a los agentes sociales que otras técnicas de investigación que impiden un contacto directo entre ambos; ahora bien, que se tengan en cuenta o no (y cómo) va a depender, en último extremo, de los marcos teórico-epistemológicos que se manejen, así como de la mayor o menor apertura y plasticidad que se les conceda a éstos durante el trabajo de campo. Resulta sintomático de lo que digo la divergencia entre los enfoques con que Lévi-Strauss y Malinowski abordaron respectivamente el tema de los mitos, pues mientras el primero los analizó como si hablaran por sí mismos, intentando descubrir en ellos una estructura homóloga a la conjeturada para la mente humana, Malinowski recalcó que las funciones del mito no provienen (ni son observables a través) de su contenido o de su estructura, sino - como recuerda Audrey I. Richards ${ }^{134}$ — de las formas en que los sujetos actúan con ellos o, dicho con un lenguaje más actualizado, de las prácticas míticas, de suerte que - por consiguiente- dichas funciones varían en cada una de ellas: el hecho es que Lévi-Strauss trabajó primordialmente con material de segunda mano, con textos mitológicos de diversa procedencia y variados compiladores, en tanto que Malinowski se dedicó al estudio de las situaciones de relatos míticos que había observado - como dicen los periodistas- 'en vivo y en directo'. Si esto no es admitido como una toma en consideración de los sujetos investigados es porque se piensa que, para que así fuera, se habrían de adoptar como explicación y/o interpretación de los fenómenos que se estudian las suministradas por aquéllos (exégesis que es abonada por el empeño con que Delgado y Gutiérrez reprochan a la OP el no conceder al ainterior de un sistema" la capacidad de "dar cuenta de sí mismo"). El quid de la cuestión está, por tanto, en cómo se le antoja a alguien - desde una mirada retrospectiva a las obras etnográficas - que los agentes sociales

133 Pp. 149-150.

134 RiCHARDS, A. I., "El concepto de cultura en la obra de Malinowski", en FIRTH, R. (comp.), Hombre y cultura en la obra de Bronislaw Malinowski (Madrid: Siglo XXI, $1997-1957-)$, p. 23. 
hubieran debido ser considerados. Y con todo, algunos ejemplos de asumir como válidas las interpretaciones (o las perspectivas) de los sujetos estudiados los podemos hallar en el mismo Malinowski, o en Boas; y, más concretamente, en sus trabajos respectivos - harto divulgados- sobre el kula o el potlach, puesto que tanto el uno como el otro examinaron la economía melanesia o la kwakiutl tal como se la representaban los que participaban en ellas, lo que - entre otras cosas- les llevó a poner en solfa la universalidad de la arraigada idea - ya expuesta aquí- de que todo hombre vive dominado por el cálculo economizador.

La observación participante - como he repetido- es tanto o más adecuada que otras técnicas de investigación para la captación de la perspectiva de los sujetos. Insertada en proyectos etnográficos (que es lo que acontece generalmente), posibilita no sólo tener en cuenta tal perspectiva, sino percibir - por una parte- de qué manera va cambiando en función de las diferencias de edad, género, profesionales, económicas, etc. existentes entre los agentes sociales y - por otra - cómo va modificándose incluso en cada uno de ellos, pues el trabajo de campo antropológico da ocasión (se aproveche o no) de observarlos en situaciones distintas y, por consiguiente, también de atender a su actuación en esos contextos. Por otro lado, y por esta última razón, los etnógrafos suelen mostrar interés por el décalage que a veces se produce entre las percepciones subjetivas y las prácticas sociales de los actores, así como juzgan a menudo que las primeras no siempre constituyen explicaciones (o interpretaciones suficientes) de las segundas aunque contribuyan indudablemente a que ocurran; de ahí que las estudien. Así, si Delgado y Gutiérrez no terminan de dar crédito a tal posibilidad, o discuten que las monografías etnográficas recojan las perspectivas de los sujetos, no es —en mi opinión- por otra cosa que por entender que la única forma de no obliterarlas estriba en tomar como explicaciones y/o interpretaciones de la realidad investigada solamente esas perspectivas — tal como señalaba más arriba-, o bien porque no conciben otro modo de otorgar al "interior de un sistema" la capacidad de "dar cuenta de sí mismo" que recurriendo a la autoobservación, esto es, haciendo que los actores se conviertan después en observadores y escriban acto seguido un informe sobre ello. Pero, entonces, el debate se desplaza a otro terreno epistemológico (muy resbaladizo - por cierto-): el de si un investigador puede aproximarse a las perspectivas de los actores cuando él mismo no es - $\mathrm{O}$ no ha sido previamente- actor; un territorio que no voy a visitar ahora, porque se necesita algo más que un par de páginas de un artículo para dialogar con unos posicionamientos relativistas (los del relativismo cognoscitivo) bastante más extremos que los avivados por Winch —sobre todo- desde 1964. 
Claro está que Delgado y Gutiérrez, en el último párrafo que he transcrito, inciden menos en que se obvie a los sujetos, que en "la reducción" de la complejidad de los mismos a la hora de comprender sus acciones. Ahora bien, ¿en qué consiste exactamente ala complejidad del sujeto"? ¿y en qué su "reducción»? Pues, si esto último no significa más que enfocar "la reflexividad, los valores personales, el deseo como obstáculos para el conocimiento de la realidad global de un objeto de investigación", no me queda más remedio que colegir (con apoyo de ciertas aseveraciones que vierten en la página 150) que consiste en adoptar un enfoque objetivista, como el que Bourdieu achaca - v.g.- a Lévi-Strauss:

\begin{abstract}
El objetivismo, que se propone establecer regularidades objetivas (estructuras, leyes, sistemas de relaciones, etc.) independientes de las consciencias y de las voluntades individuales, introduce una marcada discontinuidad entre el conocimiento teórico y el conocimiento práctico, rechazando como 'racionalizaciones', 'prenociones' o 'ideologías' las representaciones más o menos explícitas con que este último se arma. Recusa así el proyecto de identificar la ciencia social con una descripción científica de ese mundo o, más precisamente, el proyecto de reducir la ciencia social, como hacen Schütz y la fenomenología, a 'construcciones de segundo orden, o sea, construcciones de las construcciones producidas por los actores en la escena social' o, como Garfinkel y la etnometodología, a 'informes de los informes (accounts) que producen los agentes ${ }^{135}$.
\end{abstract}

Si es así, traeré a colación que los primeros trabajos empíricos del sociólogo galo, tanto como los de Bateson, que les dan pie a ambos para extraer conclusiones como, por ejemplo, la de que la cultura mitológica [o el simbolismo ritual] puede llegar a ser el instrumento y, en ocasiones, la meta de estrategias extremadamente complejas, incluso en sociedades que no disponen de un aparato religioso fuertemente desarrollado y diferenciado, son precisamente investigaciones etnográficas que incluyen, por serlo, la observación participante: vide, para más señas, las que el segundo realizó en Nueva Guinea (que desembocaron en su gran obra Naven ${ }^{136}$ ), y que empezaron siendo dirigidas por Haddon, Malinowski y RadcliffeBrown, o las que el primero llevó a cabo en el norte de Argelia y en el Bearne francés. Es decir, que a partir de las reflexiones sobre un material originado en la etnografía, Bateson consigue no sólo superar el modelo funcionalista de los dos antropólogos que he mentado en último lugar (de los que critica la clase de explicación de los fenómenos socioculturales que proporcionan), sino también idear una interpretación que combina los aspectos lógicos y afectivos que descubre en el ritual iatmul de travestismo

135 Bourdieu, El sentido práctico, edición citada (pp. 48-49).

136 Bateson, G., Naven. Análisis de un ritual iatmul (Gijón: Júcar, 1990 -1936-). 
que es objeto de su atención - lo que él llama el eidos y el ethos de la cultura iatmul一, así como crear el sugestivo concepto de cismogénesis, que más tarde perfilará en su teoría del "doble vínculo" de la esquizofrenia y que entiende como un proceso de diferenciación resultante de un conjunto de interacciones acumulativas entre individuos; un concepto - no lo olvidemos- que propone para describir las relaciones dinámicas (entre hombres y mujeres, consanguíneos y afines, etc.) que son representadas en un ritual que él conoció en su condición de etnógrafo. En lo que se refiere a Bourdieu (ver, v.g. el libro 2 de El sentido práctico), aunque menos proclive que Bateson a hacer entrar elementos afectivos en sus explicaciones, sospecho que no se le pueda clasificar entre quienes desdeñan la perspectiva de los sujetos o no reconocen su complejidad; es más, en sus escritos derivados del trabajo de campo que efectuó en la Cabilia argelina (adonde llegó con un bagaje primordialmente estructuralista) y en el mencionado departamento francés de los Pirineos, se explaya mostrando las intrincadas y, en ocasiones, alambicadas estrategias que despliegan los individuos para alcanzar ciertos objetivos en el terreno del parentesco, el matrimonio, la economía, la demografía, el honor, el mito o los rituales; unas estrategias que, desde su punto de vista, responden a una lógica práctica nunca ajena a las constricciones y posibilidades que brinda la estructura social. Así, para Bourdieu, como para bastantes otros que han seguido sus planteamientos, el estudio de esta última constituye una parte fundamental de la investigación, pero que no excluye el de las significaciones que los fenómenos de que se trate tienen para los sujetos, por cuanto - como él dice, aunque en una época en que ya había descuidado la práctica etnográfica-: "a diferencia de las ciencias naturales, una antropología total no puede detenerse en una construcción de relaciones objetivas porque la experiencia de las significaciones forma parte de la significación total de la experiencia" ${ }^{137}$. En suma, nos encontramos con que los etnógrafos (correspondan a la disciplina social que sea) se han enfrentado al problema de la perspectiva de los sujetos y de su complejidad de las maneras más heterogéneas que uno pueda discurrir, tratándolo - además- con ópticas diferentes conforme su pensamiento ha ido evolucionando o según los temas que han abordado en cada momento: desde quienes, como Gregory Bateson o Víctor Turner ${ }^{138}$, han optado por integrar en sus interpretaciones el tono emocional y/o sensorial de la vida, hasta quienes - como Bourdieu, Comas o Devillard - han ponderado más la lógica -si bien práctica- de las estrategias de los actores, sin dejar

137 Bourdieu, Chamboredon y Passeron, op. cit., pp. 34-35.

138 TuRnER, V., La selva de los símbolos (Madrid: Siglo XXI, 1980 -1967-). 
tampoco de analizar los factores estructurales que las hacen posible; o desde quienes han visto aquella perspectiva ya sea como algo sin trascendencia teórica (Lévi-Strauss es un caso) ya sea como algo que hay que dilucidar desde un enfoque etic (Harris, verbigracia), pues no se la percibe como la explicación que se busca de la realidad que se estudia, hasta quienes han considerado que el único sentido de tal realidad es el que le dan sus protagonistas, como sucede con la concepción de los símbolos que han mantenido Frederick Nadel y Mónica Wilson, contraria a la del ya nombrado Turner, que quiere integrar la visión de los actores con la del investigador.

Variando ligeramente de asunto: la afirmación de Delgado y Gutiérrez acerca de que en la antropología cultural "se espera del nativo un comportamiento racional isomorfo de la concepción de la racionalidad del analista", aparte de parecerme contradictoria con respecto a lo que aseguran justo antes [que la OP reduce "el nivel de subjetividad y reflexividad del objeto (grupo humano investigado) por debajo del nivel de subjetividad y reflexividad del sujeto investigadorn], me remite inexorablemente - también por un cierto aire de familia - a las propuestas teóricas de Malinowski ${ }^{139}$ sobre la magia trobiandesa, de Evans-Pritchard ${ }^{140}$ sobre las creencias azande en brujería, de Lévi-Strauss ${ }^{141}$ sobre el pensamiento salvaje o de Harris ${ }^{142}$ sobre el misterio de la vaca sagrada hindú. El primero, como es de sobra conocido, defendió la racionalidad de las prácticas mágicas fundamentándola en el hecho de que éstas cumplen funciones de vital importancia para el individuo, precisamente porque "la magia aparece cada vez que los elementos aleatorios y accidentales y el juego emocional entre esperanza y temor se presentan en una amplia y extensa variedad... (y) no la observamos, en cambio, cuando el objetivo es claro y fácilmente asequible con métodos racionales". El segundo sostuvo asimismo la racionalidad de las creencias en brujería, pero acudiendo esta vez a interpretaciones sobre todo cognoscitivas ${ }^{143}$, pues - para EvansPritchard- tales creencias son un modo distinto de explicar las desgracias, un modo que se caracteriza por ser lógico, tan lógico como lo pu-

139 Malinowski, B., Magic, science and religion (Nueva York: Doubleday, Garden City, 1948).

140 EVANS-PRITCHARD, E., Magia, oráculos y brujeria entre los azande (Barcelona: Anagrama, 1976 -1937-).

141 LÉvi-Strauss, C., El pensamiento salvaje (México: FCE, 1977 —1954-).

142 Harris, M., "The cultural ecology of India's cattle". Current Antbropology, n. 7 (1966).

143 Lo que no quita para que también mostrara la función social que desempeñan. 
diera ser la ciencia occidental, pero que arranca de premisas diferentes y que se ocupa de lo concreto (de saber por qué le sucede algo a una persona en particular). Lévi-Strauss lo que hizo fue, desde mi punto de vista, generalizar al "pensamiento salvaje" la tesis que Evans-Pritchard había centrado en el estudio de ciertas creencias y prácticas del pueblo sudanés que escogió como campo de investigación, e integrarla en un marco teórico distinto - el estructuralista-, como deja ver no sólo la cita que le dedica al antropólogo británico en la página 27 de El pensamiento salvaje, sino también las siguientes palabras:

(N)o retornamos a la tesis vulgar (por lo demás, admisible, en la perspectiva estrecha en la que se coloca), según la cual la magia sería una forma tímida y balbuciente de la ciencia: porque nos privaríamos de todo medio de comprender el pensamiento mágico, si pretendiésemos reducirlo a un momento, o a una etapa, de la evolución técnica y científica.. [] El pensamiento mágico no es un comienzo, un esbozo, una iniciación, la parte de un todo que todavía no se ha realizado; forma un sistema bien articulado, independiente, en relación con esto, de ese otro sistema que constituiría la ciencia..[] Por tanto, en vez de oponer magia y ciencia, sería mejor colocarlas paralelamente, como dos modos de conocimiento, desiguales en cuanto a los resultados teóricos y prácticos.., pero no por la clase de operaciones mentales que ambos suponen, y que difieren menos en cuanto a la naturaleza que en función de las clases de fenómenos a las que se aplican ${ }^{144}$.

En cuanto a Harris, es público y notorio que busca la racionalidad de determinados "enigmas de la cultura" en las adaptaciones ecológicas que encierran, en las funciones que desempeñan para que los ecosistemas se mantengan dentro de los márgenes de su capacidad de sustentación, tal como -en su primer artículo sobre el tema al igual que en obras divulgativas posteriores- asegura que ocurre con el mencionado de la vaca sagrada:

Todo el mundo está de acuerdo en que la población humana de la India necesita más calorías y proteínas. No obstante, la religión hindú prohíbe el sacrificio de ganado vacuno y hace un tabú del consumo de su carne. A menudo, se responsabiliza a estos tabúes de la creación de gran número de vacas viejas, decrépitas, estériles o inútiles. Se describe a estos animales como si no hicieran otra cosa que vagar sin objeto alguno por los campos de la India, obstruyendo las carreteras, deteniendo trenes, robando alimentos en el mercado y bloqueando las calles de la ciudad. Un examen más minucioso de algunos de los detalles del ecosistema del subcontinente indio sugiere, sin embargo, que el tabú en cuestión no disminuye la capacidad del actual sistema indio de producción de alimentos para mantener la vida humana ${ }^{145}$.

144 LÉVI-STRAUSS, op. cit., p. 30.

145 HARRIS, M., Introducciōn a la antropología general (Madrid: Alianza, 1990 -1985-), p. 478. 
En definitiva, estos etnógrafos pusieron un énfasis especial en dejar patente que los fenómenos que investigaban y, por ende, también los sujetos que los protagonizaban, eran racionales; una racionalidad que, independientemente de la consciencia de éstos (no negándola o ignorando su punto de vista), el investigador puede descubrir en ellos. Si, al mismo tiempo, cargaron excesivamente las tintas en un cierto isomorfismo u homología (que no analogía) entre esos fenómenos y la racionalidad del propio investigador, esto encuentra su sentido en un contexto intelectual muy específico y se debe a una intención muy concreta: recusar la irracionalidad o ilogicidad que bastantes de sus predecesores, coetáneos y compatriotas (incluídos algunos eruditos y científicos) atribuían a prácticas sociales dispares de las propias. Ahora bien, nada de ello supone que desecharan "las divergencias hacia la categoría de lo imaginario, místico, mágico, etc., como se puede comprobar si uno se fija tan sólo en los temas que abordaron, sino que perseguían hacer inteligible lo que no tenía apariencia de serlo, recurriendo para ello a la razón porque - como no estaban aún de moda los escritos de Castaneda o de Tyler- no podían ni soñar que las exégesis imaginarias, místicas o mágicas tuvieran capacidad de sustituirla o fueran aceptadas por la comunidad científica a la que pertenecían. Por otro lado, sería una gran osadía suponer que Malinowski y Evans-Pritchard no prestaron atención a la consciencia o a las preocupaciones de los sujetos sociales so pretexto de (o precisamente por) defender la racionalidad detectable en los fenómenos socioculturales que estudiaron; salvo en el caso — claro está- de que, para serles reconocido el honor de haberlo hecho, fuera imprescindible hallar en sus trabajos huellas de los enfoques de la "cibernética de segundo orden" o el lenguaje finisecular de "la autoorganización", "la construcción", "los fractales", "el caos" y la "polifonía". Esto es, pretender que Malinowski, Evans-Pritchard, LéviStrauss o Harris, entre otros, se hubieran interesado por los mismos aspectos de los agentes sociales y reflejaran en las monografías su reflexividad, consciencia o deseos de la misma manera en que, por ejemplo, lo hacen Bourdieu, Geertz y otros, o lo plantean Morin, Von Foerster o Depuy, no sería más que querer que Harris renegara del materialismo cultural, Lévi-Strauss del estructuralismo y que Malinowski o Evans-Pritchard hicieran suyos unos marcos teórico-epistemológicos que no surgieron hasta varias décadas después de que publicaran sus etnografías más sobresalientes y que, además, nacieron en buena medida gracias a la reflexión crítica que se generó en torno a los que tanto ellos mismos como otros de sus contemporáneos utilizaron o propusieron.

Me sorprende que Delgado y Gutiérrez, tan preocupados por el noreconocimiento de la reflexividad, la heterogeneidad y la apertura de los 
sujetos investigados, se resistan a reconocer esas mismas reflexividad, heterogeneidad y apertura en los sujetos investigadores, sean éstos etnógrafos o no, aunque quizá sea debido a que tampoco consideran importante la reflexividad, la heterogeneidad y la apertura - y perdóneseme el trabalenguas- de los sujetos que investigan a los sujetos investigadores. Lo de "la observación participante practica..", "la antropología cultural se encarga..., "la investigación antropológica considera... y frases de este tenor son muchas veces inevitables cuando se escribe o habla, y sería algo inane si correspondiera simplemente a un rasgo de un cierto estilo literario (o a la generalización de algo generalizable), pero tiene consecuencias más graves y falseadoras cuando tácitamente va acompañado de determinados postulados, como el de conjeturar que los aludidos por tales proposiciones constituyen un bloque compacto de actores sociales que se conforman con seguir los pretendidos dictados de su disciplina. En definitiva, olvidan que cualquier ciencia social no es, en realidad, más que el variado conjunto de los presupuestos epistemológicos, constructos teóricos, estrategias metodológicas o prácticas de investigación de todos y cada uno de sus componentes (buena parte de los cuales - isiempre hay algún despistado! - no viven, por otra parte, en una 'burbuja disciplinaria'). O, dicho de otro modo, a lo largo de su análisis de la antropología y de la observación participante, Delgado y Gutiérrez no hacen sino incurrir en los errores de los que precisamente las acusan, otro de los cuales es sin duda - la reificación de conceptos (el de investigación antropológica o el mismo de OP), a los que no sólo conceden "estatuto ontológico y gran capacidad para orientar la acción social" de los antropólogos, sino el poder demiúrgico de engendrar por sí solos las nociones (culturas, identidades) que supuestamente éstos emplean.

\section{A MODO DE CONCLUSIÓN}

A. Vallejo, psicóloga que se encargó de impartir varias sesiones en septiembre de 1997 dentro de un curso sobre educación infantil organizado por el Instituto Comenio, contaba que de nada sirve decirle a un niño "No te metas en los charcos, que te constipas". El niño seguirá metiéndose en los charcos, porque habrá comprobado por propia experiencia que sólo en contadas ocasiones se ha enfermado por ello. La razón - según comentaba- estriba en que, en frases como la anterior, se omite el razonamiento de todo el proceso. Habría que decirles: "No te metas en los charcos, porque si te metes en ellos, te mojarás; si te mojas, estarás en contacto con la ropa húmeda, y si no te cambias rápidamente, es posible 
que te constipes". No resulta nada fácil resistir la tentación de identificarse con el niño de los charcos: si no se aclara o razona el proceso a partir del cual una determinada práctica o una determinada metodología (aquí, la observación participante) conlleva unas ciertas implicaciones 'nefastas' o contribuye a 'deformar' el objeto de estudio, se siente legitimado a seguir utilizándola como una práctica o una metodología válida. Me explicaré mejor. En la página 142, v.g., Delgado y Gutiérrez citan —entre otros- el trabajo de Bourdieu para apoyar su convicción sobre "el carácter difuso.. de la separación nominalista de lo cuantitativo y lo cualitativo", y podrían haberlo hecho también para mostrar un antecedente de lo que buscan con el artículo: poner de manifiesto que "toda elección metodológica construye su objeto de estudio". Esto último lo argumenta magníficamente el sociólogo francés en lo que atañe - por ejemplo- al método genealógico; Rosaldo, aunque de manera algo menos convincente - a mi parecer-, por lo que afecta a la observación participante efectuada en pequeñas comunidades o Marie Jose Devillard en lo que se refiere al trabajo de campo prolongado e intensivo. El problema, entonces, estriba en que Delgado y Gutiérrez nos hablan de (y valoran negativamente) "charcos" y "constipados", sin dilucidarnos por qué no son buenos ni en qué circunstancias unos llevan a otros.

En suma, no he pretendido decir en ningún momento - como he anunciado antes- que las técnicas o las metodologías de investigación no tengan un papel en la construcción del objeto de estudio, sino recalcar que ese papel, en lo que se refiere a la observación participante, no ha sido desvelado suficientemente por Delgado y Gutiérrez. Si se hace caso a la historia de la antropología (y no exclusivamente a ella), es fácil ver que no es la observación participante - considerada aisladamente de los marcos teóricos de los que se parte, de las condiciones concretas de su práctica y del grado de vigilancia epistemológica que se ejerce- la que lleva a generar nociones como "subjetividad cultural" (si es que fuera propia de nuestra disciplina), de "cultura" como sistema cerrado ni a la reificación de conceptos como este último o "identidad"; y una prueba de ello - en la que he insistido- se halla en que se trata de conceptos que no han utilizado así todos los investigadores que han practicado la observación participante ${ }^{146}$, al mismo tiempo que son o han sido producidos

146 Valgan también de ejemplos los casos clásicos - que me ha rememorado Ana Rivas mientras escribía esto- de Mead y Freeman, o de Redfield y Lewis, que practicando la OP sobre la mismas poblaciones, realizaron análisis y llegaron a conclusiones diferentes; o el de los antropólogos interesados por el tema de la identidad regional y nacional que optan por el concepto de 'etnicidad' frente a los que eligen el de 'identidad colectiva', sin que ni unos ni otros dejen de utilizar la OP. 
y/o compartidos por otros que en absoluto lo han hecho (ya sean antropólogos, sociólogos o psicólogos sociales). Ya he tenido ocasión, más atrás, de mostrar mis dudas con respecto a la asociación necesaria de tales ideas (concepción cerrada de sistema, objetivismo y noción de cultura como un todo homogéneo) con la OP, así como el hecho de que bastantes etnógrafos —entre otros- las han criticado hace ya tiempo, si bien vinculándolas, más que con la observación participante, con formas específicas de llevarla a cabo (inmersión primitivista en una sola comunidad, centrándose en informantes-clave, no recurriendo a información externa...); unas formas que junto a otras como la de asumir como precepto metodológico lo de comportarse durante el trabajo de campo como un ignorante ingenuo, sin tener la lucidez suficiente de darse cuenta de que ese papel sólo es aceptable por los sujetos estudiados en determinadas situaciones, es lo que provoca relevantes dificultades (de orden metodológico y/o de índole personal) a la hora de aplicar la observación participante en la investigación de cualquier tipo de sociedad, incluidas las "simples", porque las así denominadas no lo son tanto como se tiende a presuponer.

El objetivo que guía el análisis de Delgado y Gutiérrez de la observación participante parece dirigido a mostrar la inaplicabilidad de ésta al estudio de las sociedades complejas, por las supuestas implicaciones epistemológicas y teóricas que - en su opinión- tiene. Para ello, conectan la OP a la antropología social y cultural, pero únicamente para rechazar su adecuación no sólo al estudio de las sociedades complejas - que es lo que expresamente destacan-, sino a cualquier estudio, como se puede entresacar si el lector no se queda en lo meramente explícito y extrae las consecuencias lógicas que se desprenden de las premisas que fundamentan todo su edificio narrativo. De camino, casan a la OP, y con ella a la antropología, con paradigmas caducos y anticuados, al tiempo que ensalzan las virtudes 'tardocibernéticas' de su propuesta metodológica: la autoobservación. Es más, todo este movimiento se hace a costa de no hacer justicia a la heterogeneidad de las teorizaciones antropológicas y de las prácticas etnográficas, así como a partir de una atribución ilegítima a la OP de planteamientos teóricos y epistemológicos correspondientes únicamente a algunos de sus practicantes o corrientes de pensamiento que, para Delgado y Gutiérrez, se convierten en implicaciones o premisas de la OP.

Quiero terminar estos comentarios con otra idea de Bourdieu que, desde mi punto de vista, es aplicable tanto a lo que aquellos dos autores llaman "observación exógena" como a lo que denominan "observación endógenan: 
La relación práctica que el etnólogo mantiene con su objeto, la del extranjero excluido del juego real de las prácticas sociales porque no tiene que hacerse en él un lugar, es el límite y la verdad de la relación que el observador, lo quiera o no, lo sepa o no, mantiene con su objeto; el estatus de espectador que se retira de la situación para observarla implica una ruptura epistemológica, pero también social, que nunca gobierna tan sutilmente la actividad científica como cuando deja de aparecerse como tal, conduciendo a una teoría implícita de la práctica correlativa al olvido de las condiciones sociales de posibilidad de la actividad científica. La situación del etnólogo recuerda la verdad de la relación que todo observador mantiene con la acción que enuncia y analiza: a saber, la ruptura insuperable con la acción y el mundo, con los fines inminentes de la acción colectiva, con la evidencia del mundo familiar, que supone la misma intención de decir la práctica y, sobre todo, de comprenderla y hacerla comprender de otro modo que produciéndola y reproduciéndola prácticamente. No hay, si se sabe qué quiere decir hablar, discurso de acción: no hay más que un discurso.. que dice la acción y que, a riesgo de caer en la incoherencia o la impostura, no debe dejar de decir que sólo dice la acción ${ }^{147}$.

Si es una ilusión pensar que la participación, propugnada por la OP, puede superar esa ruptura epistemológica, también lo es postular que lo pueda conseguir la AO. No es cuestión de sustituir la participación primitivista por lo que podríamos calificar, a falta de un nombre mejor, de participación endogenista, sino de estar atentos a los efectos que se derivan, a la hora de construir el objeto de estudio, de la posición social de observador, una posición social que —en este sentido, al menos - varía poco por el hecho de que el observador esté previamente 'dentro' o 'fuera' del grupo o de la situación investigada.

147 BOURDIEU, El sentido prâctico, edición citada, pp. 60-61. 
El artículo intenta establecer las características de la observación participante, para lo cual se toma como hilo conductor de la exposición la crítica de un texto, publicado en 1994, donde se defiende la tesis de que la técnica emblemática de la antropología social es inadecuada para el estudio de las sociedades complejas. Con el objeto de rebatir esta idea, se analizan las supuestas 'condiciones' de la observación participante, al tiempo que se hace una propuesta de distinción terminológica entre los diferentes conceptos de 'distancia' manejados por los representantes de la disciplina. Paralelamente, se pone de manifiesto que bastantes de los problemas metodológicos y epistemológicos que se achacan habitualmente a la observación participante $o$, en general, a la etnografía, no se derivan inexorablemente de la propia técnica o metodología de investigación, sino de los presupuestos teóricos que el etnógrafo utiliza explícita e implícitamente durante sus indagaciones.

The article is an attempt to establish the characteristics of participant observation. For that purpose, a critical essay on a text published in 1994 is taken as the main line of the exposition. That text upholds the thesis that the emblematic method of social anthropology is inappropiate for the study of complex societies. In order to rebut this thesis, the ostensible conditions of participant observation are analysed. This article also provides a terminological distinction between the different concepts of distance that anthropologists consider. Subsequentlly, it is shown how methodological and epistemological problems, which are usually attributed to ethnography and participant observation, do not necessarily derive from them. In fact, such problems stem from theoretical presuppositions that are explicitly and implicitly used by ethnographers during their research. 